San Jose State University

SJSU ScholarWorks

Master's Theses

Master's Theses and Graduate Research

Fall 2014

\title{
The Role of Type A Behavior Pattern on the Stressor-Strain Relationship in Nurses
}

Jenny Anh Thu Le

San Jose State University

Follow this and additional works at: https://scholarworks.sjsu.edu/etd_theses

\section{Recommended Citation}

Le, Jenny Anh Thu, "The Role of Type A Behavior Pattern on the Stressor-Strain Relationship in Nurses" (2014). Master's Theses. 4501.

DOI: https://doi.org/10.31979/etd.f4c7-qtfz

https://scholarworks.sjsu.edu/etd_theses/4501

This Thesis is brought to you for free and open access by the Master's Theses and Graduate Research at SJSU ScholarWorks. It has been accepted for inclusion in Master's Theses by an authorized administrator of SJSU ScholarWorks. For more information, please contact scholarworks@sjsu.edu. 


\title{
THE ROLE OF TYPE A BEHAVIOR PATTERN ON THE STRESSOR-STRAIN RELATIONSHIP IN NURSES
}

\author{
A Thesis \\ Presented to \\ The Faculty of the Department of Psychology \\ San José State University \\ In Partial Fulfillment \\ of the Requirements for the Degree \\ Master of Science
}

by

Jenny A. Le

December 2014 
(C) 2014

Jenny A. Le

ALL RIGHTS RESERVED 
The Designated Thesis Committee Approves the Thesis Titled

THE ROLE OF TYPE A BEHAVIOR PATTERN ON THE STRESSOR-STRAIN RELATIONSHIP IN NURSES

by

Jenny A. Le

APPROVED FOR THE DEPARTMENT OF PSYCHOLOGY

SAN JOSÉ STATE UNIVERSITY

December 2014

Dr. Sharon Glazer

Dr. Howard Tokunaga

Dr. Altovise Rogers
Department of Psychology

Department of Psychology

Department of Psychology 


\title{
ABSTRACT \\ THE ROLE OF TYPE A BEHAVIOR PATTERN ON THE STRESSOR-STRAIN RELATIONSHIP IN NURSES
}

\author{
by Jenny A. Le
}

Three models (direct effects, moderated effects, and mediated effects) were used to test the role of Type A Behavior Pattern (TABP) in the stressor-strain relationship. The longitudinal study measured stressors (role ambiguity, role overload, and role conflict), strains (anxiety, tedium, affective commitment, intent to leave, and general well-being), and TABP in hospital nurses across two survey administrations. Stressors at Time 1 and strains at Time 2 were utilized for the analyses. TABP was found to have direct effects on anxiety and general well-being. In addition, TABP partially moderated the relationship between role conflict and anxiety and tedium, as well as the relationship between role overload and anxiety, tedium, and general wellbeing. No support was found for the mediator relationship. These findings suggest that Type A nurses experience greater anxiety, tedium, and lower general well-being in response to high role conflict and role overload than Type B nurses. 


\section{ACKNOWLEDGEMENTS}

First and foremost, I would like to extend my sincere appreciation and gratitude to Dr. Sharon Glazer for her enduring patience and support over the (admittedly) long years it took to finally complete my thesis. Sharon, thank you for your encouragement, expert perspective and advice, especially since and in spite of having moved on in your career! To my second reader, Dr. Howard Tokunaga, I would like to express my appreciation for the "gentle" nudges to finish up. Howard, your encouragement and support truly shows your care toward your students, regardless of the amount of time that has passed. To my third reader, Dr. Altovise Rogers, I would like to say 'thank you' for lending your time and expertise!

Despite having taken a bit longer than anticipated, I am proud to have accomplished this work. Thank you to my friends, family, and coworkers who have supported me throughout! I appreciate all of your efforts to question, threaten, bribe, and coax me on my thesis - you have all helped me get to this point. Last but not least, I would not be where I am today without my husband. For the love and support you provided, for the frustration and annoyance you've tolerated, and for your continued encouragement every step of the way - thank you, thank you, and thank you! 


\section{TABLE OF CONTENTS}

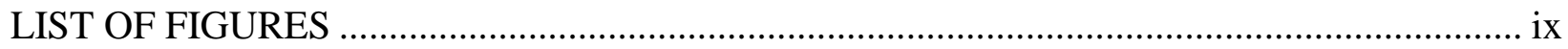

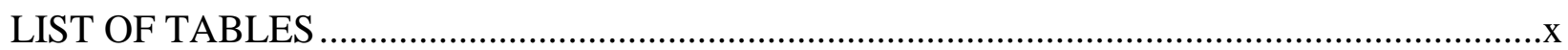

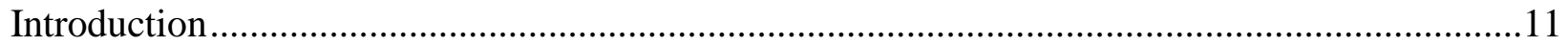

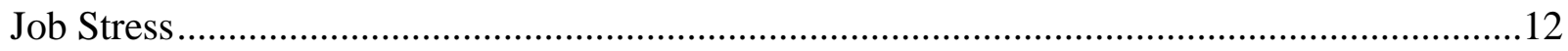

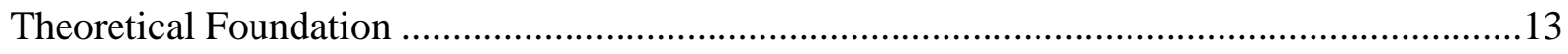

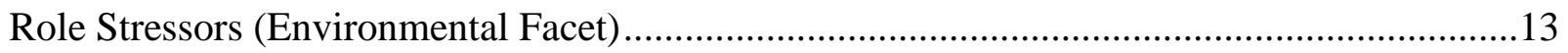

Strains (Human and Organizational Consequences Facets) .....................................................15

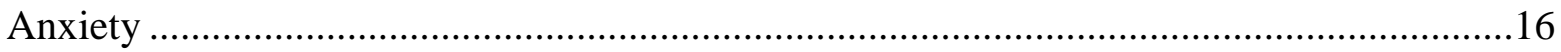

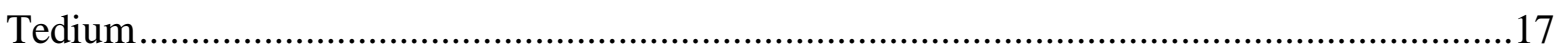

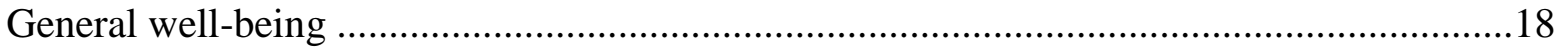

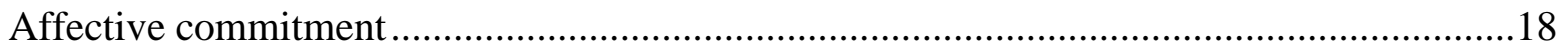

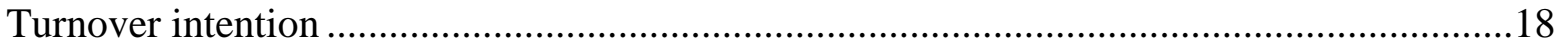

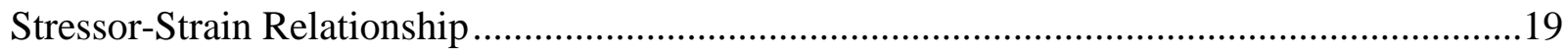

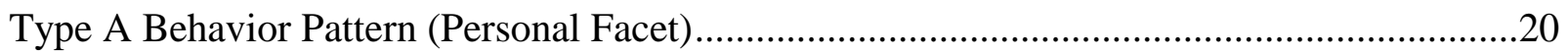

TABP in Relation to Stressors and Strains.............................................................................

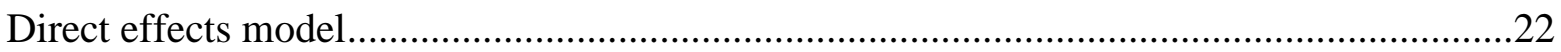

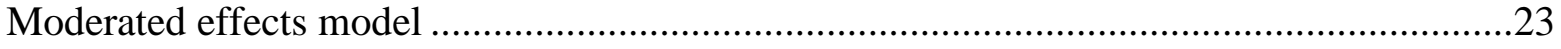

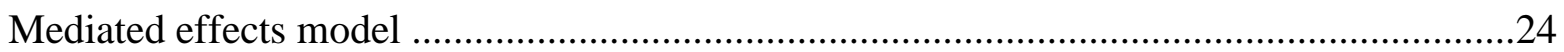

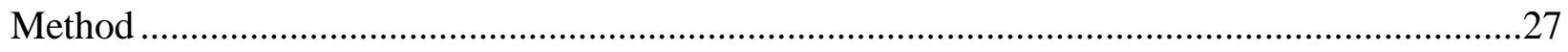

Sample

Procedure

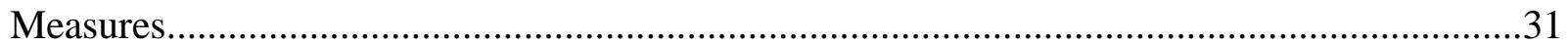




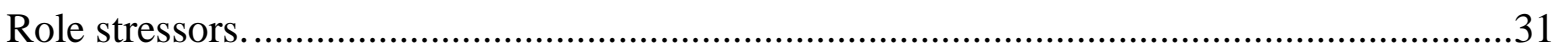

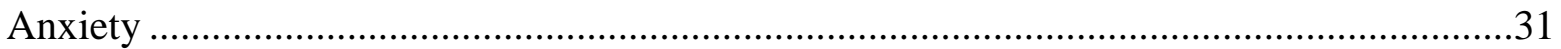

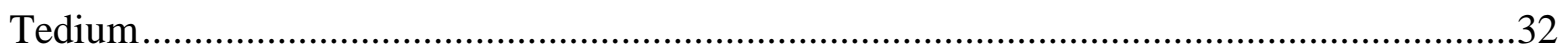

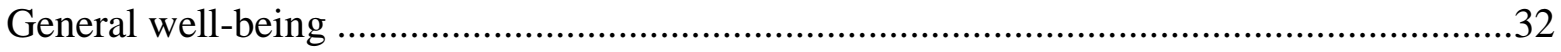

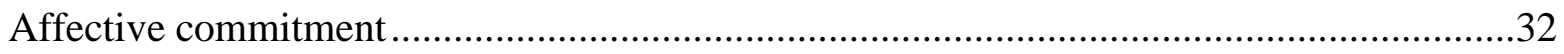

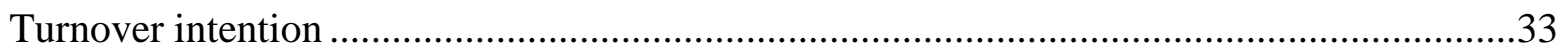

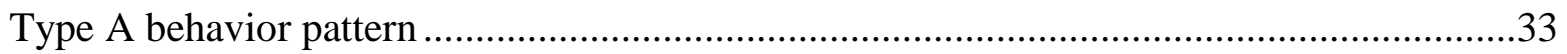

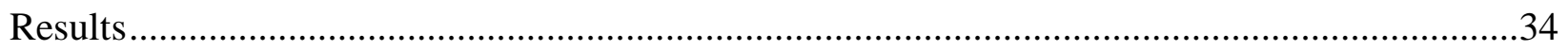

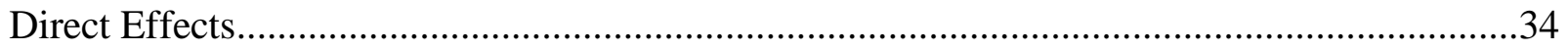

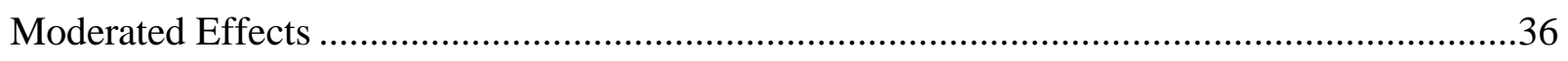

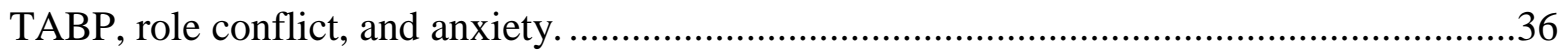

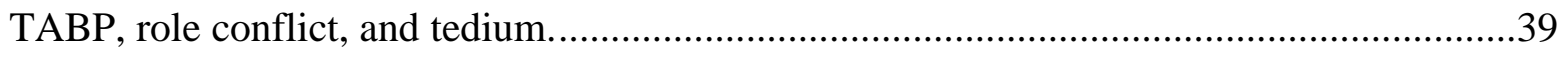

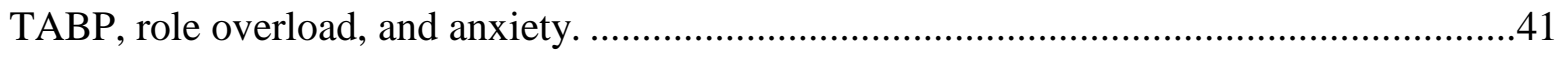

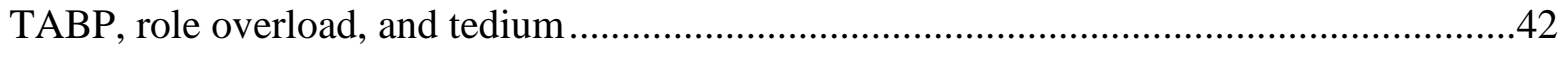

TABP, role overload, and general well-being ........................................................44

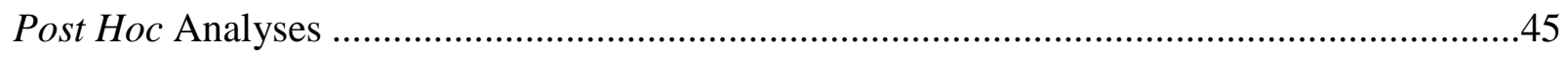

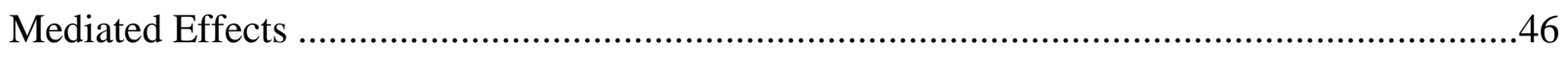

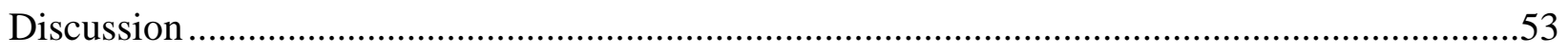

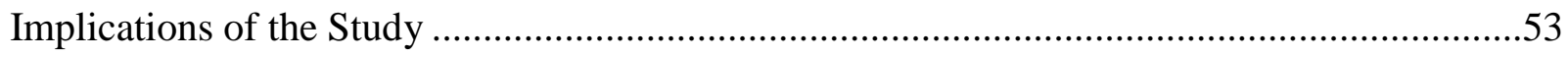

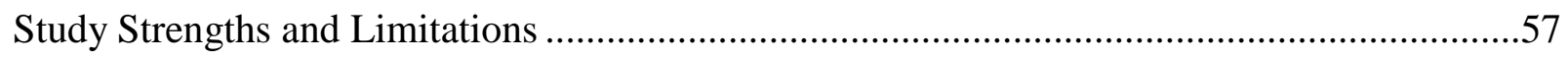

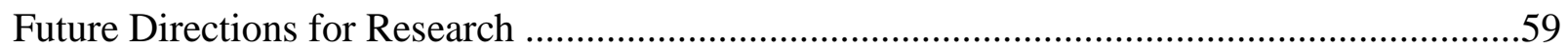

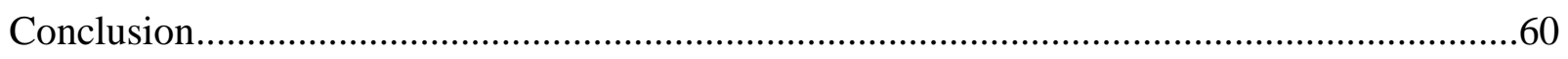

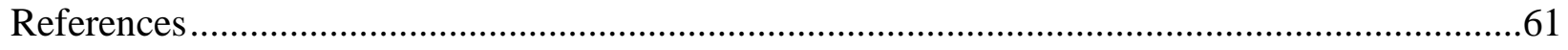


Appendix A: Study Measures .. 


\section{LIST OF FIGURES}

Figure 1. Beehr and Newman's (1978) facet model of occupational stress. ..............................14

Figure 2. Illustration of the role of TABP on occupational stress in the direct effects, moderated effects, and mediated effects models.

Figure 3. Interaction between TABP and role conflict on anxiety. ....................................40

Figure 4. Interaction between TABP and role conflict on tedium.......................................41

Figure 5. Interaction between TABP and role overload on anxiety. .....................................42

Figure 6. Interaction between TABP and role overload on tedium....................................43

Figure 7. Interaction between TABP and role overload on general well-being. .......................45

Figure 8. Baron \& Kenny's (1986) mediation model.......................................................51 


\section{LIST OF TABLES}

Table 1 Frequencies and Means of Demographic Variables.

Table 2 Means, Standard Deviations, Reliabilities (on diagonal in bold), and Correlations Among

Study Variables, Controlling for Hospital .35

Table 3 Interaction Between Role Stressors, and Type A on Anxiety, Tedium, and General Well-

Being .37

Table 4 Interaction Between Role Stressors, and Type A on Affective Commitment and Intent to

Leave .38

Table 5 Interaction Between Role Stressors and TABP on Anxiety and General Well-Being - T1

Post Hoc Analysis

Table 6 Interaction Between Role Stressors and TABP on Affective Commitment and Intent to

Leave - T1 Post Hoc Analysis

Table 7 Interaction Between Role Stressors and TABP on Anxiety, Tedium, and General Well-

Being - T2 Post Hoc Analysis

Table 8 Interaction Between Role Stressors and TABP on Affective Commitment and Intent to

Leave - T2 Post Hoc Analysis .50

Table 9 Tests of stressors as a mediator of the relationships between TABP and Strains .52 


\section{Introduction}

The concept of "stress" is now common nomenclature, with a very personal meaning to each person. The word "stress" comes up frequently in everyday conversation as people talk about dealing with "stress" at work, in personal relationships, while working on personal finances, handling information technology, managing personal fears, and navigating changes among so many other things. In particular, job stress is an important focus for organizational research because of its potential influence on employees' mental and physical health and also because of its repercussions for organizational effectiveness (Leatt \& Schneck, 1985).

Job stress is estimated to cost U.S. industries more than $\$ 300$ billion a year in absenteeism, turnover, diminished productivity, and medical, legal, and insurance costs (Rosch, 2001). More conservatively, Azagba and Sharaf (2011) estimated that the health care utilization induced by stress costs U.S. companies $\$ 68$ billion annually. According to the National Institute for Occupational Safety and Health (NIOSH) (1999), health care expenditures for workers who report high levels of stress are nearly $50 \%$ greater than the average employee. Additionally, in a 2004 publication, NIOSH reported that anxiety, stress, and related disorders result in a greater number of days taken off work than non-fatal workplace injuries or illnesses. In a survey by the American Psychological Association (2009), 24\% of Americans report high levels of stress and $51 \%$ report moderate levels of stress, which represents $75 \%$ of the surveyed population.

According to a 2012 Stress in America survey by The American Psychological Association, Americans consistently report experiencing stress at levels higher than what they perceive is healthy.

One group that endures a great deal of stress is nurses. Numerous researchers report that the nursing profession is inherently stressful (Guppy \& Gutteridge, 1991; Healy \& McKay, 
1999; Kirkcaldy \& Martin, 2000; Wu, Zhu, Wang, Wang, \& Lan, 2006). The nursing profession could be considered particularly stressful as nurse staffing in many countries is characterized by shortage and understaffing (World Health Organization, 2011). There are several factors attributing to the nursing shortage in the U.S., including the aging nursing workforce (HRSA, 2010), insufficient supply of new nursing graduates (Duvall \& Andrews, 2010), and nurses leaving the professions due to job-related stress (Chan, Tam, Lung, Wong, \& Chau, 2013).

In a literature review of job stress among nurses, Chang, Hancock, Johnson, Daly, and Jackson (2005) found that factors associated with role stress include having little control in one's job, high job demands and low supportive relationships, dealing with death and dying, being moved among different patient care units within the organization, shortage of essential resources and nursing staff, and work overload. Due to the stress inherent to the nursing profession, Vredenburgh and Trinkaus (1983) claim nurses are a particularly suitable population for the study of occupational role stress. In this paper, I focus on the effects of specific role stressors (role ambiguity, role conflict, and role overload) on specific strains (anxiety, tedium, general well-being, affective commitment and turnover intention) among nurses, by examining the role of individual characteristics (Type A Behavior Pattern).

\section{Job Stress}

Job stress is a complex phenomenon resulting from the interaction of personal, sociocultural, and organizational factors. According to Jex (2002), researchers have adopted a stimulus-response definition in studying job stress. Associated with the stimulus aspect of this definition, stressors represent aspects of the work environment which might require an adaptive response. Related to the response aspect of the definition, strains refer to the wide array of 
maladaptive ways that reactions to stressors can be manifested, such as anxiety, tedium, poor general well-being, low organizational commitment, and high turnover intent.

Alone, stressors do not always lead to strains. Instead, stressors will lead to strains when the stressors are perceived to be a threat. Moreover, influencing whether stressors are perceived as a threat depends on the person and the environment. According to the transactional model of stress (Lazarus \& Folkman, 1984), characteristics of the person and of the environment play a role in determining how or when stressors lead to strains. This framework also stipulates that work conditions often influence the kinds of stressors that arise. In this paper, I present literature on stressors, strains, and properties of the person - specifically Type A Behavior Pattern (TABP), and present research hypotheses on how these variables relate to each other.

\section{Theoretical Foundation}

This study borrows from Beehr's and Newman's (1978) Facet Model of Occupational Stress. According to the model, shown in Figure 1, the core relationship of occupational stress consists of causal effects of the environmental facet on the human consequences facet. The environmental facet can be job stressors (e.g., role stressors) and the human consequences facet are individual strains (e.g., anxiety, tedium, general well-being, affective commitment and turnover intention) (Beehr, 1995).

\section{Role Stressors (Environmental Facet)}

Role stress is based on the assumption that all individuals perform roles, which are comprised of the behavioral expectations for a position within a social structure (Örtqvist \& Wincent, 2006). In other words, an individual's role comprises the behavioral requirements and limitations expected of that individual by others associated with that role. In an organizational context, these figures can be supervisors, subordinates, colleagues, or even family members who 


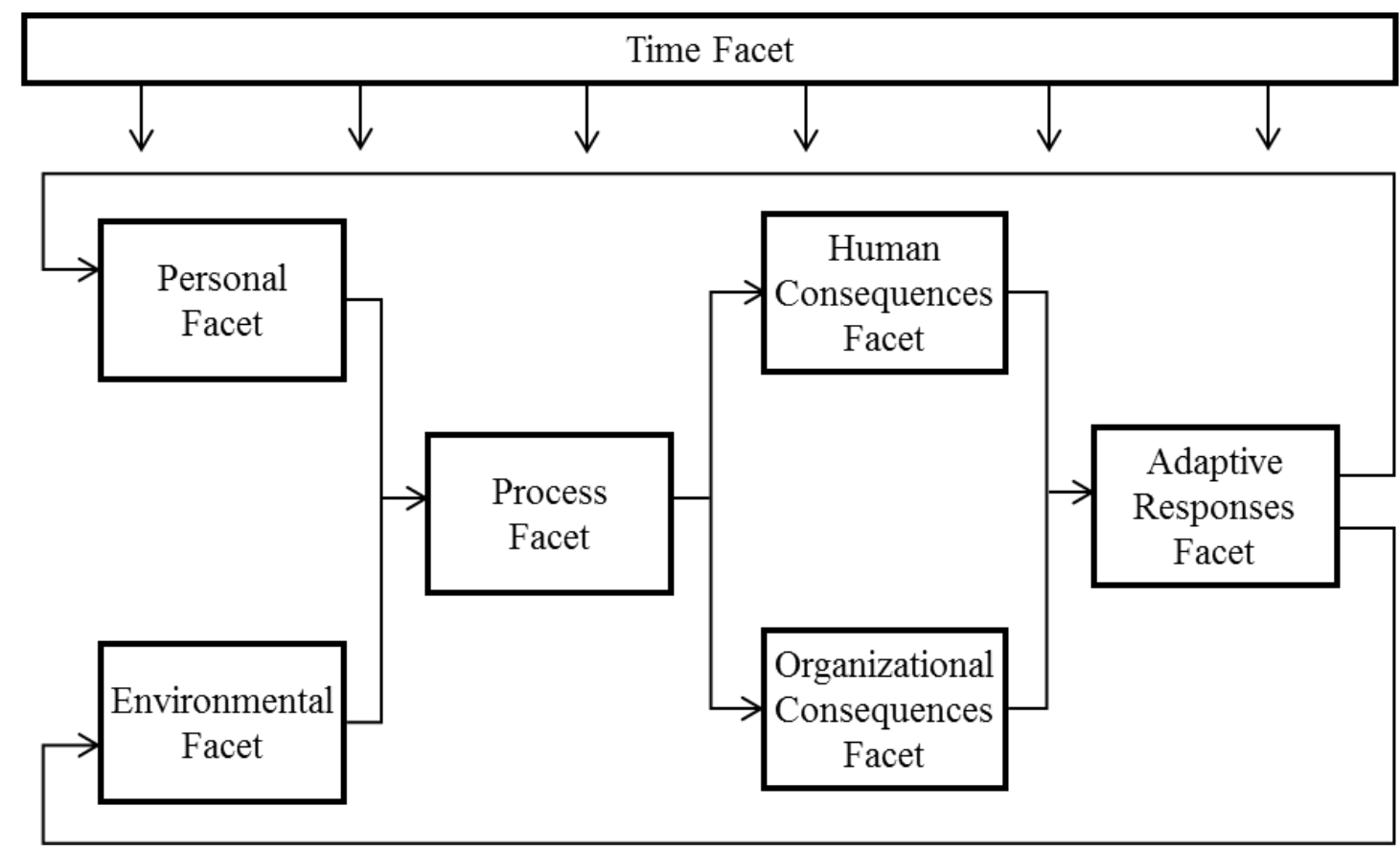

Figure 1. Beehr and Newman's (1978) facet model of occupational stress depicting the relationship between the personal and environmental facets (i.e., stressors) lead to the human and organizational consequences facets (i.e., strains). Adapted from "Job Stress, Employee Health, and Organizational Effectiveness: A Facet Analysis, Model, and Literature Review," by T. A. Beehr, \& J. E. Newmam, 1978, Personnel Psychology, 31, p. 676. Copyright 2006 by John Wiley and Sons.

may be affected by an individual's work life. When the individual perceives the expectations of the role to be ambiguous, conflicting, or overburdening, such perceptions can be considered role stressors (Beehr \& Glazer, 2005). Role stressors fall under the psychosocial domain of stress because the social environment shapes one's role (Jex, 2002). If such expectations are perceived as threatening or unmanageable, strains will occur (Beehr \& Glazer, 2005).

Role ambiguity, role conflict, and role overload are the most widely studied role stressors in the organizational stress research (Beehr \& Glazer, 2005). Role ambiguity occurs when rolerelated information is unclear or lacking (Kahn, 1980). That is, the information one has and the information required to perform one's role are not compatible. Role conflict arises when there are two or more sets of incompatible expectations on an individual, particularly when fulfilling 
one set of expectations makes fulfilling the other set more difficult (Beehr, 1995). Lastly, role overload occurs when the demands on an employee are more than he or she can accomplish within a given time or are thought to be excessive (Jex, 2002). Researchers have differentiated between two types of role overload: quantitative and qualitative. Quantitative overload is experienced when there is too much to do or too much is expected of an employee in a given time; whereas qualitative overload is experienced when the work required or what is expected of an employee is beyond his or her capabilities or resources (Kahn, 1980). In this paper, quantitative overload and qualitative overload is not differentiated.

\section{Strains (Human and Organizational Consequences Facets)}

Empirical studies indicate that organizational stressors have detrimental effects (i.e., strains) on the individual as well as the organization (Fisher \& Gitelson, 1983; Gilboa, Shirom, Fried, \& Cooper, 2008; Jackson \& Schuler, 1985; Jex, 2002; Kahn, 1980). There are three categories of strains in occupational stress research: physical, behavioral, and psychological. Physical strains are bodily reactions to stressors, which include changes in physical health and well-being (Beehr \& Glazer, 2005). Coronary heart disease, perspiration, poor sleep quality, fatigue, and body aches are examples of physical strains (or human consequences). Behavioral strains are behaviors an individual shows in reaction to stressors that are harmful to the individual (Beehr, 1995; Beehr \& Glazer, 2005). Examples of behavioral strains include alcohol or drug consumption, over or under-eating, and engaging in violent behaviors.

Behavioral strains can also have negative consequences for the organization. In Beehr's and Newman's (1978) occupational stress model, individual behavioral strains that affect the organization are included in the organizational consequences facet. Some examples of organizational strains are absenteeism, reduced productivity or job performance, and turnover. 
Psychological strains are reactions to stressors that are mentally experienced, which include affective and emotional responses (Beehr \& Glazer, 2005). Some examples of psychological strains include anxiety and tedium (which are human consequences) and affective commitment and turnover intention (which are organizational consequences). Although affective commitment is a positive attitude, when people are not committed to their workplace, it is a potential indicator of strain. As Jex and Beehr (1991) point out, low affective commitment is an organizational consequence that is considered a strain (see also Beehr \& Glazer, 2005). Like affective commitment, turnover intention is an indicator that something in the organization is not working. That 'something' is often identified as work-related stressors. Ajzen and Fishbein (1977) explain that behavioral intention is the primary antecedent to actual behavior, inferring that the cognitive process of turnover intention is an important predictor of actual turnover. The strains examined in this paper include anxiety, tedium, general well-being, low affective commitment and low turnover intention; each of these strains is discussed below.

Anxiety. Anxiety is an "emotional response of fear in anticipation of a noxious stimulus" (Taylor, 1951, p. 82). In this study, anxiety is operationalized as the distress or unease one feels in response to one's job (Muschalla, Linden, \& Dieter, 2010). A number of studies on occupational stress have directly examined anxiety as an outcome of job stressors (Beehr \& Newman, 1978; Caplan \& Jones, 1975; Ganster \& Rosen, 2013; Glazer, 2005; House \& Rizzo, 1972; Ivancevich \& Matteson, 1980; Jamal \& Baba, 1992; Newton \& Keenan, 1990; Totterdell, Wood, \& Wall, 2006). Two meta-analyses (Fisher \& Gitelson, 1983; Jackson \& Schuler, 1985), reported that the average correlation between role ambiguity and anxiety was .19 and .30, respectively; the average correlation between role conflict and anxiety was .28. Spector, Chen, 
and O'Connell (2000) found a correlation of .21 between role overload and anxiety. According to the research, high levels of role stressors seem to result in higher levels of anxiety.

Tedium. Pines, Aronson, and Kafry (1981) define tedium as the general experience of physical, emotional, and mental exhaustion, which is characterized by the negation of one's self, one's environment, one's work, and one's life. Tedium is related to another strain measure called burnout. Burnout is emotional exhaustion and cynicism that often occurs among individuals who work continuously with people (Maslach \& Jackson, 1981). Though tedium and burnout are similar in their resulting symptoms, they differ on the basis of origin. Pines and colleagues suggest that tedium can be the result of prolonged chronic pressures which are mental, physical, or emotional, whereas burnout can occur due to continual emotional pressure resulting from intense involvement with people over long periods of time (Maslach, Schaufeli, \& Leiter, 2001). Thus, it appears that burnout represents one aspect of tedium. One of the subscales of the Maslach Burnout Inventory, a popular instrument used to measure burnout, is emotional exhaustion (Maslach \& Jackson, 1981). In this study, the emotional exhaustion subscale of burnout will be used in relation with tedium.

Role ambiguity and role conflict have both been found to positively correlate with tedium (Stout \& Posner, 1984). The relationship between role ambiguity and tedium was moderate ( $r=$ $.42)$; whereas the relationship between role conflict and tedium was low $(r=.21)$. Green, Albanese, Shapiro, and Aarons (2014) found strong positive correlations between role conflict and emotional exhaustion $(r=.66)$, and between role overload and emotional exhaustion $(r=$ .67); a moderate negative correlation was found between role clarity (which is the opposite of role ambiguity) and emotional exhaustion $(r=.30)$. In fact, the correlations between role 
stressors and the emotional exhaustion dimension was the strongest of all the burnout dimensions.

General well-being. General well-being is operationalized as psychological well-being, characterized by a lack of psychological distress. Vandenberghe et al. (2011) stipulate that an individual's cognitive appraisal of environmental stressors may lead to perceived threat, thus leading to psychological distress. Jex and Elacqua (1999) and Parkes (1990) both found a moderate correlation between role conflict $(\mathrm{r}=.30)$ and role overload $(\mathrm{r}=.29)$ and general wellbeing. Payne, Wall, Borrill, and Carter (1999) found similar findings for all three roles stressors - role clarity $(\mathrm{r}=.27)$, which is the reverse of role ambiguity, role conflict $(\mathrm{r}=.33)$, and role overload $(\mathrm{r}=.33)$.

Affective commitment. Affective commitment is an employee's identification with, involvement in, and emotional attachment to the organization (Meyer \& Allen, 1991). In a metaanalytic review, Örtqvist and Wincent (2006) found that role ambiguity, role conflict, and role overload negatively correlated with organizational commitment. Matieu and Zajac (1990) found that the three role stressors moderately correlated with affective commitment at $-.22,-.27$, and .21 , respectively. Vandenberghe et al. (2011) replicated the findings of this meta-analysis for affective commitment; however, studies by Stanley, Herscovitch, and Topolnytsky (2002) and Ackfeldt and Malhotra (2013) found positive relationships for affective commitment with only role ambiguity and role conflict.

Turnover intention. Turnover intention is conceived as the conscious and deliberate willfulness to leave one's organization (Mowday, Koberg, \& McArthur, 1984). Research suggests that there is a higher turnover tendency among employees with higher levels of stress (Fang \& Baba, 1993; Jackson \& Schuler, 1985). Furthermore, Fang (2001) found that stress 
exerted the most substantial impact on turnover intention of all the variables measured (i.e., demographic variables, job satisfaction, supervisor satisfaction, organizational commitment, and professional commitment). In a meta-analytic reviews, Örtqvist and Wincent (2006) and Podsakoff, LePine, and LePine (2007) found that stressors (including role ambiguity, role conflict, and role overload) positively related to turnover intentions. Vandenberghe et al. (2011) found a strong positive relationship between both role conflict $(r=.33)$ and role ambiguity $(r=$ .34) with turnover intentions. Anton (2009) found a relationship only for role conflict and turnover intentions. While actual turnover data are quite difficult to obtain, self-report intentions to turnover can be captured in a self-report survey. Moreover, Ajzen and Fishbein explained that of turnover intention is an important predictor of actual turnover behavior.

\section{Stressor-Strain Relationship}

The research reviewed thus far lends support to the relationship outlined in Beehr's and Newman's (1978) model of occupational stress describing a causal effect of the environmental facet (i.e., stressors) on the human or organizational consequences facet (strains). Most of the studies examining stressor-strain relationships have utilized cross-section data, whereby stressors are measured at the same point in time as strains. The use of cross-sectional, self-report designs allows researchers only to conclude that relations exist among the job and employee variables studied (Spector, Chen \& O'Connell, 2000). One of the challenges of a cross-sectional design is the inability to determine causal relationships. When using a cross-sectional design, the assumption is that the variables measured are stable across time (Bowen \& Wiersema, 1999). For example, when testing the relationship between stressors and strains measured at the same time, it is assumed that the stressors measured are influencing the strains as opposed to stressors that previously occurred having a delayed influence. This study is intended to provide a stronger 
test of role stressor-strain relationship than has been provided by the typical cross-sectional design as longitudinal designs allow for support of more causal conclusions between predictor and outcome variables (Gelsema, et al. (2006). Data will be analyzed using role stressors measured at Time 1 and strains measured at Time 2.

Based on the above review of stressors and strains, I hypothesize that:

$\mathrm{H}_{1}$ : Role stressors (role ambiguity, role conflict, and role overload) at Time 1 will positively correlate with anxiety, tedium, and turnover intent and negatively correlate with general well-being and affective commitment at Time 2 .

\section{Type A Behavior Pattern (Personal Facet)}

Along with organizational facets (e.g., affective commitment and turnover intentions), the Beehr and Newman (1978) model of organizational stress also emphasizes the importance of the personal facet, "which consists of the employees' relative stable characteristics that affect perceptions, appraisals, or reactions to stress" (Beehr, 1995, p. 18). The personal facet includes individual variables that influence how people view situations. Such individual difference factors can be personality types or behavior patterns; one such behavior pattern is the Type A Behavior Pattern (TABP).

Two cardiologists, Friedman and Rosenman (1974), conceptualized TABP when studying patients suffering from cardiac illness. They proposed a correlation between cardiovascular disease and a set of personal traits, which they called Type A Behavior Pattern. They described TABP as an "action-emotion complex that can be observed in any person who is aggressively involved in a chronic, incessant struggle to achieve more and more in less and less time, and if required to do so, against the opposing efforts of other things and other persons" 
(Friendman \& Rosenman, 1974, p. 67). Additionally, Friedman and Rosenman wrote that Type A individuals are prone to a sense of time urgency and can exhibit hostility when provoked by some environmental trigger. In contrast, Type B behavior pattern is defined by a lack of the Type A characteristics and can be described as more relaxed and easy-going. Matthews (1982) specifies that TABP is not considered a trait but rather a set of overt behaviors that is elicited from susceptible individuals by the environment. Ivancevich and Matteson (1984) state that it is important to distinguish TABP from the concept of stress as TABP is not a stressor nor a distressed response. Rather, TABP is a response pattern.

Berry (1998) suggested that organizational psychologists are particularly interested in TABP for two reasons. First, TABP and cardiovascular disease positively relate (Friedman \& Rosenman, 1974), such that Type As are more likely to experience cardiovascular disease. Berry further notes that aspects of the work environment, including opportunities for achievement, deadlines, or perceived competition, often elevate the Type A person's activity level, which might actuate cardiovascular disease. Second, studies have shown that Type A individuals have higher work performance and accomplishments than Type Bs. Thus, certain individuals might show chronic high arousal and develop an associated cardiovascular problem due to their inclination to take on more work responsibilities coupled with organizational reinforcement (e.g., added responsibilities) to do more work.

\section{TABP in Relation to Stressors and Strains}

Bolger and Zuckerman (1995) suggest that personal variables might affect an individual's exposure to stressful events, how that individual reacts to those events, or both. Kivimaki, Kilimo, and Julkunen (1996) summarized the alternate models that have been proposed for the 
role of TABP on occupational stress: the direct effects model, the moderated effects model, and the mediated effects model (see Figure 2).

\section{Direct Effects Model}

$\mathrm{TABP} \longrightarrow$ Strains

\section{Moderated Effects Model}

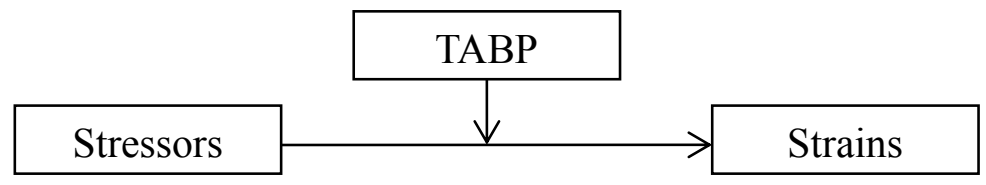

\section{Mediated Effects Model}

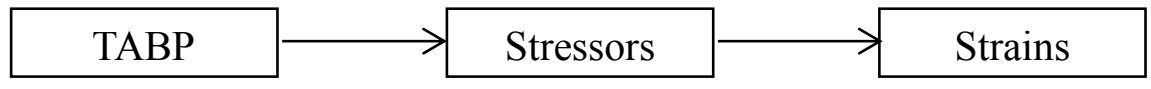

Figure 2. Illustration of the role of TABP on occupational stress in the direct effects, moderated effects, and mediated effects models.

Direct effects model. The direct effects model suggests that TABP increases the number of symptoms (i.e., strains) one experiences regardless of the amount or type of stressors one perceives. Jamal and Baba (2003) examined the direct effect of TABP on both individual and organizational outcomes. Of specific interest to my proposed study, they looked at individual outcomes in terms of job stress, which they operationalize as feelings of anxiety; and organizational outcomes in terms of organizational commitment, and turnover motivation, which is related to turnover intent. They found that TABP positively correlated with job stress and turnover motivation; and negatively correlated with organizational commitment and job satisfaction. Similarly, Burke (1988) studied the direct effect of TABP on stain variables such as burnout, which they do not differentiate emotional exhaustion; general well-being, which they call personal well-being; and turnover intention. He found support for a direct effect of TABP on burnout, personal well-being, but not for turnover intention. 
Moderated effects model. The moderated effects model suggests that TABP moderates the stressor-strain relationship such that the relationship between stressors and strains is stronger for Type A individuals than for Type B individuals. In addition to examining the direct effects model, Burke (1998) also looked at the moderating effect of TABP on burnout, personal wellbeing, and emotional exhaustion. He hypothesized that the relationships between role ambiguity and role conflict and strains is stronger for Type As than Type Bs. However, no significant interactions were found, thus, providing no support for the moderating effects of TABP on the stressor-strain relationship.

Keenan and McBain (1979) studied the moderating effect of Type A on the relationships between role stressors (role ambiguity, role conflict, and role overload) and job tension, which they operationalize as work-related feelings of anxiety. They found partial support for a moderated effect of TABP. Specifically, they found that the relationship between role conflict and job tension was not greater for Type As compared to Type Bs. However, the relationship between role ambiguity and job tension was significantly greater for Type As than Type Bs.

Caplan and Jones (1975) also tested the moderating effects model via a longitudinal study capitalizing on the impending shut-down of a university computer lab. They examined the effect of TABP on the relationship between role overload, which they operationalized as quantitative workload, and role ambiguity on anxiety. They hypothesized that as stressors increased due to the coming computer lab closure, strain increases more dramatically for Type As than Type Bs. Participants were recruited to complete a questionnaire three days before the impending computer lab shut down and then, again three months later. Caplan and Jones did in fact find a moderated relationship, where changes in role overload and changes in anxiety from Time 1 to Time 2 was greater for Type A individuals than for Type B individuals. 
Jamal (1990) tested the moderated effects model and found TABP moderated the relationship between role stressors (role ambiguity, role conflict, and role overload) and turnover motivation. More specifically, the results indicated that as role stressors increased, Type A individuals exhibited higher turnover motivation than Type B individuals. In a later study, Jamal (1999) found further support of a moderating effect of TABP, where Type Bs reported significantly less burnout as a consequence of high role stressors than Type As.

In their study, Newton and Keenan (1990) examined the moderating effect of TABP in the relationship between changes in role stressors (role ambiguity, role conflict, and role overload) and changes in anxiety. They found an interaction effect between TABP, role stressors and anxiety; however, contrary to expectations, Type B individuals reported greater anxiety with increased stressors. The authors infer four possible explanations: 1) Type A individuals might suppress feelings of psychological strain when faced with increased role stressors; 2) Type A individuals might be more adept at dealing with increased role stressors as they tend to be more ambitious, competitive, and aggressive; 3) Type As might simply like behaving in an ambitious, aggressive, and competitive way, thus they report greater satisfaction and less strain in demanding environments; or 4) the study might have captured only a low or moderate level of role stressors, and perhaps Types As would report greater strains than Type Bs when faced with higher demand conditions than those reported in the study.

Mediated effects model. The mediated effects model suggests that TABP influences strains through stressors, such that TABP accentuates perceived stressors, thus leading to greater strains. In other words, Type As experience or perceive more stressors, which leads to greater strains. Van den Berg and Schalk (1997) examined a mediated effects model, hypothesizing that the relationship between TABP and general well-being is mediated by work overload. They 
found that the relationship between TABP and well-being was partially mediated by work overload, suggesting that Type A individuals tend to overload themselves with work, leading to increased workload and thus to poorer subjective well-being. The interaction between TABP and work overload had no effect on well-being, indicating that Type As were not more vulnerable to work overload than Type Bs, thus ruling out a moderator effect. Van den Berge and Schalk concluded that in general, Type A individuals either perceive their work as more demanding or make their work more demanding than Type Bs.

In other words, despite the relationship between work overload and well-being remaining the same for Type As and Type Bs, Type As generally experience or perceive more workload. Dearborn and Hastings (1987) drew similar conclusions from their study. Type As rated their jobs as significantly more stressful than Type Bs. After controlling for researchers' objective ratings of job stress for the participants' jobs, Type As' ratings of their jobs were still significantly higher than the ratings of Type Bs. Dearborn and Hastings also found that Type As tended to report more psychological strains (e.g., general well-being) than Type Bs. They proposed that Type A individuals have a predisposition to appraise situations as more stressful than Type B individuals, lending support to the mediated effects model.

The research on the effects of TABP on the stressor-strain relationship is inconclusive with support found for a direct effect, moderated effect, and mediated effect of TABP. In this paper, I will test and explore all three models of the role Type A plays in the stress process as presented in Kivimmaki, Kalimo, and Julkunen (1996).

$\mathrm{H}_{2}$ : TABP will have direct effects on strain-related variables. Specifically, as Type A behavior pattern increases, anxiety, intention to leave the 
organization, and burnout will increase, but affective commitment and general well-being will decrease.

H3: TABP will moderate the relationship between role stressors and strains such that as stressors increase, strains will increase more strongly for Type As than Type Bs.

H4: Stressors will mediate the relationship between TABP and strains, such that most of the variance TABP accounts for in strains will be explained by stressors. 


\section{Method}

\section{Sample}

Participants were registered nurses (RNs) working at two hospitals in Northern California. The study was a longitudinal design with two survey administrations separated by about four weeks. At Time 1 (T1), 1,738 surveys were administered; 303 nurses completed the survey, yielding a response rate of $17.43 \%$. At Time 2 (T2), 1,738 surveys were again administered, with 225 nurses completing the survey (a 12.95\% response rate). A total of 137 nurses (matched through a unique self-generated identifiable code) completed both T1 and T2 surveys.

Of the 137 nurses who completed both T1 and T2 surveys, $58.39 \%$ were White, $18.98 \%$ were Asian, $10.22 \%$ were of other ethnicities, and $12.41 \%$ did not respond. Participants varied in age from 24 to 71 years of age, with a mean of 50.31 years $(\mathrm{SD}=10.13)$; and $94.16 \%$ were female. Additionally, $50.36 \%$ of the nurses worked eight-hour fixed day shifts, $1.46 \%$ worked 8 hour fixed evening shifts, $5.11 \%$ worked eight-hour fixed night shifts, $21.90 \%$ worked twelvehour fixed from 7AM to 7PM, 8.76\% worked twelve-hour fixed shift from 7PM to 7AM, 4.38\% worked staggered shift, and $4.38 \%$ did not respond. Table 1 presents the frequencies of the aforementioned demographic variables. 
Table 1.

Frequencies and Means of Demographic Variables

\begin{tabular}{|c|c|c|c|c|}
\hline Variable & & $M(S D)$ & $n$ & $\%$ \\
\hline Age (years & & $50.31(10.13)$ & & \\
\hline \multicolumn{5}{|l|}{ Gender } \\
\hline & Male & & 8 & 5.84 \\
\hline & Female & & 129 & 94.16 \\
\hline \multicolumn{5}{|c|}{ Marital Status } \\
\hline & Married/Remarried & & 87 & 63.50 \\
\hline & Divorced/Separated & & 23 & 16.79 \\
\hline & Single & & 19 & 13.87 \\
\hline & Other & & 8 & 5.84 \\
\hline \multicolumn{5}{|l|}{ Ethnicity } \\
\hline & White & & 80 & 58.39 \\
\hline & Asian & & 26 & 18.98 \\
\hline & Other & & 14 & 10.22 \\
\hline & No response & & 17 & 12.41 \\
\hline \multicolumn{5}{|c|}{ Employment Status } \\
\hline & Full & & 102 & 74.45 \\
\hline & Part & & 24 & 17.52 \\
\hline & Per diem & & 6 & 4.38 \\
\hline & No response & & 5 & 3.65 \\
\hline \multicolumn{5}{|c|}{ Job purpose } \\
\hline & Direct patient care & & 94 & 68.61 \\
\hline & Non-direct patient care & & 38 & 27.74 \\
\hline & No response & & 5 & 3.65 \\
\hline Professiona & Tenure (years) & $24.62(12.40)$ & & \\
\hline \multicolumn{5}{|c|}{ Work Pattern } \\
\hline & Fixed 8 hr Day Shift & & 69 & 50.36 \\
\hline & Fixed 8 hr Evening Shift & & 2 & 1.46 \\
\hline & Fixed 8 hr Night Shift & & 7 & 5.11 \\
\hline & Fixed 12 hr Shift (7AM - 7PM) & & 30 & 21.90 \\
\hline & Fixed 12 hr Shift (7PM - 7AM) & & 12 & 8.76 \\
\hline & Staggered Shift & & 6 & 4.38 \\
\hline & Other & & 6 & 4.38 \\
\hline & No response & & 5 & 3.65 \\
\hline
\end{tabular}

*Note. Sample size reflects participants that completed both T1 and T2 surveys. $n=137$ 
Multivariate analyses of variance (MANOVA) and chi-squared analyses were conducted to identify differences between respondents who completed T1 only and the matched sample (i.e., those who completed both $\mathrm{T} 1$ and $\mathrm{T} 2$ surveys). No significant result was obtained for the multivariate test $\left(\right.$ Wilks Lambda $=.96, F[7,286]=1.68, p>.05$, partial eta $\left.^{2}=.04\right)$. However, $^{2}$ after applying a Bonferroni adjustment, the results of the univariate analyses indicated that the matched sample reported significantly greater levels of role overload $(F[1,292]=4.26, p<.05$, partial eta $\left.^{2}=.01\right)$ and role conflict $\left(F[1,2191]=4.84, p<.05\right.$, partial eta $\left.{ }^{2}=.02\right)$ than the T1 sample. The same analyses were conducted for the T2 only sample (i.e., respondents who only completed the T2 survey) and the matched sample. A significant result was obtained for the multivariate test (Wilks Lambda $=.88, F[9,206]=3.24, p<.001$, partial eta ${ }^{2}=.12$ ). After applying a Bonferroni adjustment, the results indicated that the matched sample reported significantly greater role ambiguity $\left(F[1,214]=19.30, p<.001\right.$, partial eta $\left.{ }^{2}=.08\right)$ and role overload $\left(F[1,214]=4.47, p<.05\right.$, partial eta $\left.{ }^{2}=.02\right)$. This indicates that the matched sample used in this study reported significantly greater role overload than the respondents not used in the study (i.e., nurses who only responded to T1 or T2). In addition, the matched sample reported more role conflict than the $\mathrm{T} 1$ respondents and more role ambiguity to the $\mathrm{T} 2$ only respondents.

The survey was administered to nurses in two hospitals. Although there are reasons to expect differences between hospitals on stressors, there were no meaningful significant differences, with the exception of general well-being. The mean general well-being score for the two hospitals were 5.43 and 5.42, which was significantly different at $p<.05$. Given the differences between the means were driven by sample size, hospital was not controlled for. 


\section{Procedure}

The dataset used for this study is archival. Data were collected in June and July 2010. At the start of each survey administration, the researchers visited each hospital to deliver survey packets and survey collection envelopes. At the first hospital (Hospital 1), the researchers approached each nursing unit to deliver the surveys; whereas at the second hospital (Hospital 2), the researchers attended a nursing leadership meeting to deliver surveys to unit leads, who then distributed the surveys to nurses in their respective units. At Hospital 1, nurses were instructed to seal completed surveys in the envelopes provided with the survey and either drop them in larger collection envelopes placed in various locations throughout the hospital or to postal mail the survey to the Principal Investigator. At Hospital 2, nurses were instructed to seal completed surveys in the envelop provided with the survey and either send them via internal mail to the Chief Nurse's office or to postal mail the survey to the Principal Investigator. Research assistants collected completed surveys from the collection envelopes at Hospital 1 and the collection box at Hospital 2 at various times during the two-week survey collection period during each survey administration. A movie ticket to a local theater was attached to each T1 survey to encourage participation. As an incentive to participate in both survey administrations, nurses who completed both $\mathrm{T} 1$ and $\mathrm{T} 2$ surveys were entered into a raffle to win one of several prizes, which included a gaming console, digital camera, camcorder, GPS system, portable USB hard drive, digital photo frame, or set of movie tickets.

Participants were instructed to not provide their names, and demographic information was only asked for statistical purposes (i.e., to describe the sample). However, because this was a two-part study, the research team developed a coding system to match T1 surveys to T2 surveys. For both T1 and T2 surveys, participants were asked to provide their parents' initials to 
generate a code (e.g., Jeffrey Michael Smith and Sandra Costas yielded the code JMSSC). Additionally, to aid in matching, participants provided a self-generated identification code. To ensure that participants would be able to generate the same code at $\mathrm{T} 1$ and $\mathrm{T} 2$, a series of noninvasive personal questions were asked (e.g., "What is the first letter of the name of your elementary school? or "How many older siblings do you have?").

\section{Measures}

Data were collected using two structured surveys that consisted of a number of validated measures and some demographic questions (see Appendices B and C). The measures relevant to this current study relate to role ambiguity, role overload, role conflict, anxiety, tedium, general well-being, affective commitment, turnover intention, and Type A Behavior Pattern.

Role stressors. Role stressors were measured in both $\mathrm{T} 1$ and $\mathrm{T} 2$; however, role stressors data from $\mathrm{T} 1$ were used in the analyses. Ten items addressing role conflict, role ambiguity, and role overload were presented. These role stressors were adapted from Glazer's and Beehr's (2005) study. Role ambiguity was assessed using three items $(\alpha=.91$, see Appendix). An example item is "I have clear, planned goals and objectives for my job." Role conflict was assessed using three items ( $\alpha=.76$, see Appendix). An example item is "I do things that are apt to be accepted by one person and not accepted by others." Role overload was assessed using four items ( $\alpha=.90$, see Appendix). An example item is "I often notice a marked increase in my work load." All role stressor items were rated on a Likert-type scale ranging from 1 'strongly disagree' to 7 'strongly agree.' The role ambiguity items were reverse scored.

Anxiety. Anxiety was measured at both T1 and T2; however, anxiety data from T2 was used in the analyses. Four items of a 13-item measure, adapted from Parker and DeCotiis (1983), was used to assess job-related anxiety ( $\alpha=.90$, see Appendix). An example item is "I 
have felt fidgety or nervous as a result of my job." Job-related anxiety items were rated on a Likert-type scale ranging from 1 'strongly disagree' to 7 'strongly agree.'

Tedium. A ten-item scale adapted from Pines and Aronson (1988) was used to assess tedium $(\alpha=.90$, see items $1-10$, Appendix). An example item is "When you think about your work overall, how often do you feel tired?" Responses to these items were rated on a Likert-type scale ranging from 1 'never' to 7 'always.'

General well-being. An eleven-item scale modified from Goldberg (1972), was used to measure psychological and physical distress ( $\alpha=.84$, see items $15-25$, see Appendix). This measure was modified to be congruent with the other scales in Section I. The modified version reworded the items into "I" statements, for example, the original questionnaire had a stem followed by 12 items such as, "lost much sleep over worry." This was reworded to "I have lost much sleep over worry." The item intentionally not included was "I felt constantly under strain," because it uses the word 'stain' without operationalizing it. In addition, the scale was modified from a four-point scale ranging from 1 'not at all' to 4 'very often' to a seven-point Likert-type scale, ranging from 1 , 'strongly disagree' to 7 , 'strongly agree' in order to be consistent with the other measurement scales in the survey.

Affective commitment. Three items were used to assess affective organizational commitment, which were taken from Allen and Meyer's (1990) measure of organizational commitment ( $\alpha=.78$, see items 34,35 , and 38, see Appendix). An example item is "This organization has a great deal of personal meaning for me." Affective commitment items were rated on a Likert-type scale ranging from 1 'strongly disagree' to 7 'strongly agree' and two items were reverse scored. 
Turnover intention. Three items adapted from the Michigan Organizational Assessment Questionnaire (Cammann, Fichman, Jenkins, \& Klesh, 1979) were used to assess employees' intention to leave their jobs $(\alpha=.87$, see items 33, 36, and 39, see Appendix). An example item is "I often think about quitting." Turnover intent items were rated on a Likert-type scale ranging from 1 'strongly disagree' to 7 'strongly agree.'

Type A behavior pattern. Bortner's (1969) Type A Behavior Scale was used to assess typical behavioral patterns in everyday life. Fourteen items were used to assess TABP $(\alpha=.72$, see items 1-14, see Appendix). Participants were given a series of behaviorally anchored ratings and asked to select a number between 1 and 11 that best reflects the way they behave in everyday life. For example, for one questions, participants were asked to select a number between one and eleven - 1 indicating that they "can wait patiently;" and 11 indicating that they are "impatient when waiting." In this study Type B is operationalized as low Type A scores. 


\section{Results}

Table 2 presents the means, standard deviations, reliabilities, and correlations among the study variables, while controlling for hospital with a dummy code of 0 and 1 for the two hospitals. Of the three role stressors, participants scored significantly lower on role ambiguity $(M=2.63)$ than role conflict $(M=4.52), t(294)=-19.74, p<.001 ;$ and role overload $(M=4.44)$, $t(294)=-18.06, p<.001$. Of all the strain variables, participants reported the lowest score on tedium $(M=2.92)$ and the highest on general well-being $(M=5.39)$. In general, participants rated fairly high on TABP $(M=6.96, S D=1.29)$, considering the midpoint of the TABP scale is 5.5 .

\section{Direct Effects}

Hypothesis 1 stated that role stressors will be positively related to anxiety, tedium, and turnover intention, and negatively related to general well-being and affective commitment. To test this hypothesis, Pearson correlations were used (Table 2). All three role stressors (role ambiguity, role conflict, and role overload) significantly and positively correlated with anxiety, tedium, and intent to leave. In addition, each of the three role stressors negatively correlated with general well-being and affective commitment. Of all the strain variables, role ambiguity correlated most strongly with general well-being. Role conflict and role overload correlated most strongly with anxiety. Hypothesis 1 was supported.

Hypothesis 2 stated that Type A behavior pattern will positively correlate with anxiety, tedium, and intent to leave; and negatively correlate with general well-being and affective commitment. Type A significantly and positively correlated with anxiety, $r(220)=.24, p<.01$; and tedium, $r(220)=.26, p<.01$. TABP did not correlate with general well-being, $r(220)=-.13$, 
Table 2

Means, Standard Deviations, Reliabilities (on diagonal in bold), and Correlations Among Study Variables, Controlling for Hospital

\begin{tabular}{|c|c|c|c|c|c|c|c|c|c|c|c|}
\hline Variable & $\mathrm{M}$ & SD & 1 & 2 & 3 & 4 & 5 & 6 & 7 & 8 & 9 \\
\hline 1 Role Ambiguity (T1) & 2.63 & 1.27 & .91 & $.38 * * *$ & $.32 * * *$ & $.31 * * *$ & $.26 * *$ & $-.40^{* * *}$ & $-.27 * *$ & $.36 * * *$ & .01 \\
\hline 2 Role Conflict (T1) & 4.52 & 1.44 & & .76 & $.43 * * *$ & $.41 * * *$ & $.29 * * *$ & $-.29 * * *$ & $-.17 *$ & $.23^{* *}$ & .10 \\
\hline 3 Role Overload (T1) & 4.44 & 1.52 & & & .90 & $.42 * * *$ & $.36 * * *$ & $-.24 * *$ & $-.24 * *$ & $-.40 * * *$ & .05 \\
\hline 4 Anxiety (T2) & 3.49 & 1.60 & & & & .90 & $.61 * * *$ & $-.60 * * *$ & -.10 & $.39 * * *$ & $.24 * *$ \\
\hline 5 Tedium (T2) & 2.92 & 0.88 & & & & & .90 & $-.70 * * *$ & $-.21 * *$ & $.39 * * *$ & $26 * *$ \\
\hline 6 General Well-Being (T2) & 5.38 & 0.81 & & & & & & .84 & .28 & $-.30 * * *$ & -.13 \\
\hline 7 Affective Commitment (T2) & 4.70 & 1.35 & & & & & & & .78 & -.62 & .07 \\
\hline 8 Intent to Leave (T2) & 2.62 & 1.50 & & & & & & & & .87 & .10 \\
\hline 9 Type A Behavior (T2) & 6.96 & 1.29 & & & & & & & & & .74 \\
\hline
\end{tabular}

Notes. ${ }^{*} p<.05,{ }^{*} p<.01, * * * p<.001$. 
$p>.05$; affective commitment, $r(220)=.07, p>.05$; or intent to leave, $r(220)=.01, p>.05$. Hypothesis 2 was partially supported, indicating that TABP has a direct effect on some strains. Specifically, individuals scoring higher on TABP tend to report more anxiety and tedium.

\section{Moderated Effects}

Hypothesis 3, that Type A will moderate the relationships between role stressors and strains, was tested using hierarchical moderated regression analyses. The three role stressor variables, TABP, and the interaction between each stressor and TABP were included in these analyses. In total, 15 regression analyses were tested. Regression analyses were conducted on each T2 strain variable, where Type A was entered in step one and one stressor variable in step two to determine the unique variance accounted for by the independent variables. In step three, the interaction between Type A and one of the role stressors was added to determine the unique contributions of the Type A and role stressor interactions. The steps in each hierarchical regression analysis and are shown in Tables 3 and 4.

Within the moderated regression analyses, the interaction between role conflict and TABP accounted for significant variance in anxiety and tedium, and the interaction between role overload and TABP accounted for significant variance in anxiety, tedium, and general wellbeing. Thus, Hypothesis 3 was only partially supported. Each of these interactions is discussed further below. In the following description of the results, Type B and low Type A are used interchangeably.

TABP, role conflict, and anxiety. TABP, role conflict, and the interaction between TABP and role conflict was regressed on anxiety. For the first step, TABP was entered into the regression analysis and it accounted for $5.8 \%$ of the variance in anxiety. The overall relationship 
Table 3

Interaction Between Role Stressors, and Type A on Anxiety, Tedium, and General Well-Being

\begin{tabular}{|c|c|c|c|c|c|c|}
\hline Variable & $\beta$ & $R^{2}$ & $\operatorname{Adj} R^{2}$ & $F$ & $\Delta R^{2}$ & $F \Delta$ \\
\hline \multicolumn{7}{|l|}{ Dependent Variable: Anxiety } \\
\hline Step 1: TABP & $.24 * *$ & .06 & .05 & $8.29 * *$ & .06 & $8.29 * *$ \\
\hline Step 2: Role Ambiguity & $.31 * * *$ &. .15 & .14 & $12.15 * * *$ & .10 & $15.13 * * *$ \\
\hline Role Conflict & $.39 * * *$ & .21 & .20 & $17.66 * * *$ & .15 & $25.52 * * *$ \\
\hline Role Overload & .41 & .23 & .22 & $19.70 * * *$ & .17 & $29.36 * * *$ \\
\hline Step 3: TABP x Role Ambiguity & -.28 & .16 & .14 & $8.15 * * *$ & .01 & .28 \\
\hline TABP x Role Conflict & $1.47 * *$ & .26 & .24 & $15.45 * * *$ & .05 & $8.93 * *$ \\
\hline TABP x Role Overload & 1.24 & .26 & .24 & $15.34 * * *$ & .03 & $5.34 *$ \\
\hline \multicolumn{7}{|l|}{ Dependent Variable: Tedium } \\
\hline Step 1: TABP & $.26 * *$ & .07 & .06 & $9.75 * *$ & .07 & $9.75 * *$ \\
\hline Step 2: Role Ambiguity & $.26^{* *}$ & .13 & .12 & $10.37 * * *$ & .07 & $10.32 * *$ \\
\hline Role Conflict & $.26 * * *$ & .14 & .12 & $10.49 * * *$ & .07 & $10.53 * * *$ \\
\hline Role Overload & $.34 * * *$ & .18 & .17 & $15.00 * * *$ & .12 & $18.95 * * *$ \\
\hline Step 3: TABP x Role Ambiguity & -.21 & .14 & .12 & $6.92 * * *$ & .01 & .16 \\
\hline TABP x Role Conflict & $1.33 * *$ & .18 & .16 & $9.51 * * *$ & .04 & $6.66^{*}$ \\
\hline TABP x Role Overload & $1.23^{*}$ & .21 & .20 & $11.95 * * *$ & .03 & $4.97 *$ \\
\hline \multicolumn{7}{|c|}{ Dependent Variable: General Well-Being } \\
\hline Step 1: TABP & -.14 & .02 & .01 & 2.48 & .02 & 2.48 \\
\hline Step 2: Role Ambiguity & $-.38 * * *$ & .16 & .15 & $12.92 * * *$ & .15 & $22.96 * * *$ \\
\hline Role Conflict & $-.27 * * *$ & .09 & .08 & $6.74 * *$ & .07 & $10.81 * * *$ \\
\hline Role Overload & $-.23 * *$ & .07 & .06 & $5.08 * *$ & .05 & $7.56^{* *}$ \\
\hline Step 3: TABP x Role Ambiguity & .31 & .17 & .15 & $8.69 * * *$ & .01 & .34 \\
\hline TABP x Role Conflict & -.92 & .11 & .09 & $5.54 * * *$ & .02 & 2.95 \\
\hline TABP x Role Overload & $-1.17 *$ & .10 & .08 & $4.78 * *$ & .03 & $3.93 *$ \\
\hline
\end{tabular}

Note. ${ }^{*} p<.05, * * p<.01, * * * p<.001$. 
Table 4

Interaction Between Role Stressors, and Type A on Affective Commitment and Intent to Leave

\begin{tabular}{lcccccc}
\hline Variable & $\beta$ & $R^{2}$ & $\operatorname{Adj} R^{2}$ & $F$ & $\Delta R^{2}$ & $F \Delta$ \\
\hline Dependent Variable: Affective Commitment & & & & & \\
Step 1: TABP & .07 & .01 & -.01 & .65 & .01 & .65 \\
Step 2: Role Ambiguity & $-.29^{* * *}$ & .09 & .07 & $6.36^{* *}$ & .08 & $12.03^{* * *}$ \\
Role Conflict & $-.18^{*}$ & .04 & .02 & 2.66 & .03 & $4.66^{*}$ \\
Role Overload & -.25 & .07 & .05 & 4.67 & .06 & $8.65^{* *}$ \\
Step 3: TABP x Role Ambiguity & .18 & .09 & .07 & $4.25^{* *}$ & .01 & .10 \\
TABP x Role Conflict & -.52 & .05 & .02 & 2.07 & .01 & .88 \\
TABP x Role Overload & -.54 & .07 & .05 & 3.37 & .01 & .80 \\
Dependent Variable: Intent to Leave & & & & & & \\
Step 1: TABP & .10 & .01 & .01 & 1.38 & .01 & 1.38 \\
Step 2: Role Ambiguity & $.35^{* * *}$ & .13 & .12 & $10.30^{* * *}$ & .12 & $19.03^{* * *}$ \\
Role Conflict & $.22^{* *}$ & .06 & .05 & $4.25^{*}$ & .05 & $7.06^{* *}$ \\
Role Overload & $.40^{* * *}$ & .17 & .16 & $13.36^{* * *}$ & .16 & $25.09 * * *$ \\
Step 3: TABP x Role Ambiguity & .28 & .14 & .12 & $6.92^{* * *}$ & .01 & .28 \\
TABP x Role Conflict & .67 & .07 & .05 & $3.34^{*}$ & .01 & 1.48 \\
TABP x Role Overload & .64 & .18 & .16 & $9.36^{* * *}$ & .01 & 1.29 \\
\hline
\end{tabular}

Note. ${ }^{*} p<.05, * * p<.01, * * * p<.001$. 
between TABP and anxiety was $R^{2}=.06, F(1,134)=8.29, p<.01$. Thus, TABP and anxiety are significantly related.

For the second step, role conflict was entered into the regression analysis and accounted for $21 \%$ of the variance in anxiety. The overall relationship between the two independent variables and anxiety was $R^{2}=.21, F(2,133)=17.66, p<.001$. Thus, TABP and role conflict, as a set, were significantly related to anxiety. The added effect of role conflict was $15.2 \%, \Delta R^{2}=$ $.12, F \Delta(1,133)=25.52, p<.001$. So, adding role conflict to TABP accounted for a significant increase in the amount of variance accounted for in anxiety.

For the third step, the interaction between TABP and role conflict was entered into the regression analysis. The overall relationship between the two independent variables with the interaction and anxiety was $R^{2}=.26, F(3,132)=15.45, p<.001$. Thus, the two independent variables and the interaction between them, as a set, were significantly related to anxiety. The added effect of the interaction was $5 \%, \Delta R^{2}=.05, F \Delta(1,132)=8.93, p<.01$. The interaction between TABP and role conflict accounted for a significant increase in the amount of variance accounted for in anxiety. Figure 3 shows a plot of the slopes, which indicates that as role conflict increased, anxiety increased more strongly for Type As than Type Bs.

TABP, role conflict, and tedium. TABP, role conflict, and the interaction between TABP and role conflict was regressed on tedium. For the first step, TABP was entered into the regression analysis and it accounted for $6.7 \%$ of the variance in tedium. The overall relationship between TABP and tedium was $R^{2}=.07, F(1,135)=9.75, p<.01$. Thus, TABP and tedium are significantly related.

For the second step, role conflict was entered into the regression analysis and accounted for $13.5 \%$ of the variance in tedium. The overall relationship between the two independent 
variables and tedium was $R^{2}=.14, F(2,134)=10.49, p<.001$. Thus, TABP and role conflict, as a set, were significantly related to tedium. The added effect of role conflict was $6.8 \%, \Delta R^{2}=.07$, $F \Delta(2,134)=10.53, p<.001$. So, adding role conflict to TABP accounted for a significant increase in the amount of variance accounted for in tedium.

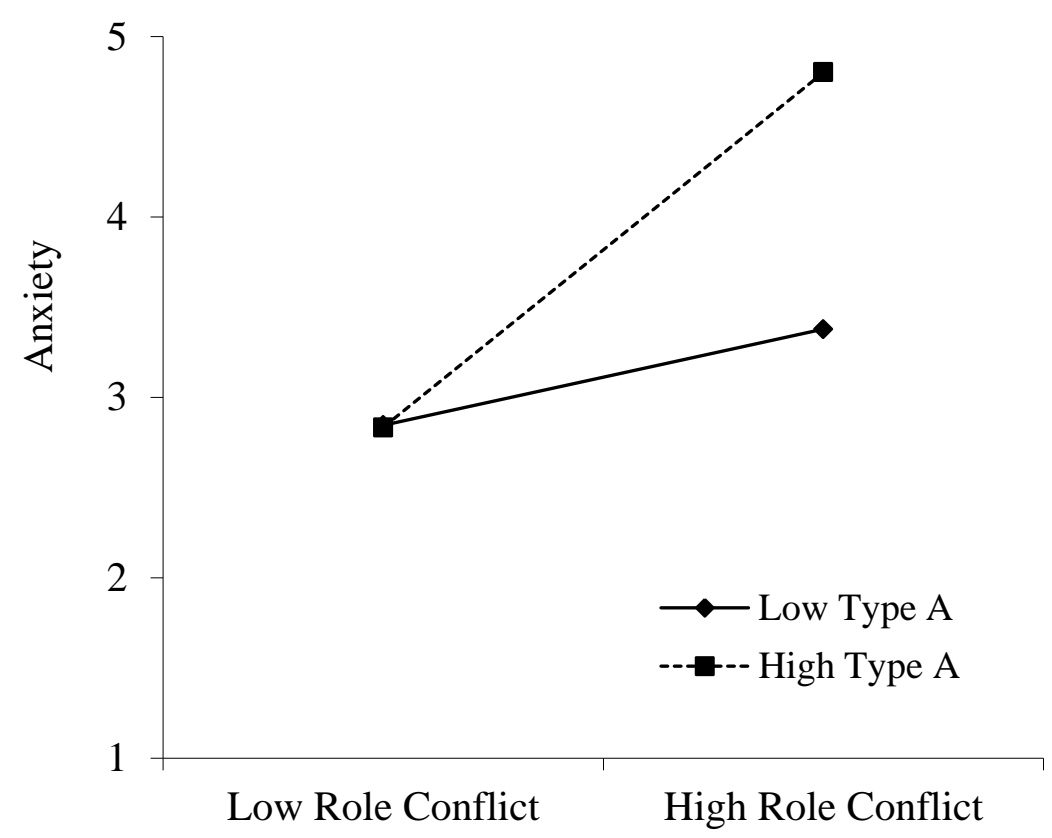

Figure 3. Interaction between TABP and role conflict on anxiety.

For the third step, the interaction between TABP and role conflict was entered into the regression analysis and accounted for $17.7 \%$ of variance in tedium. The overall relationship between the two independent variables with the interaction and tedium was $R^{2}=.18, F(3,133)=$ $9.51, p<.001$. Thus, the two independent variables and the interaction between them, as a set, were significantly related to tedium. The added effect of the interaction was $4.1 \%, \Delta R^{2}=.04$, $F \Delta(3,133)=6.66, p<.01$. The interaction between TABP and role conflict accounted for a significant increase in the amount of variance accounted for in tedium. Figure 4 shows a plot of 
the slopes, which indicates that as role conflict increased, tedium increased more strongly for Type As than Type Bs.

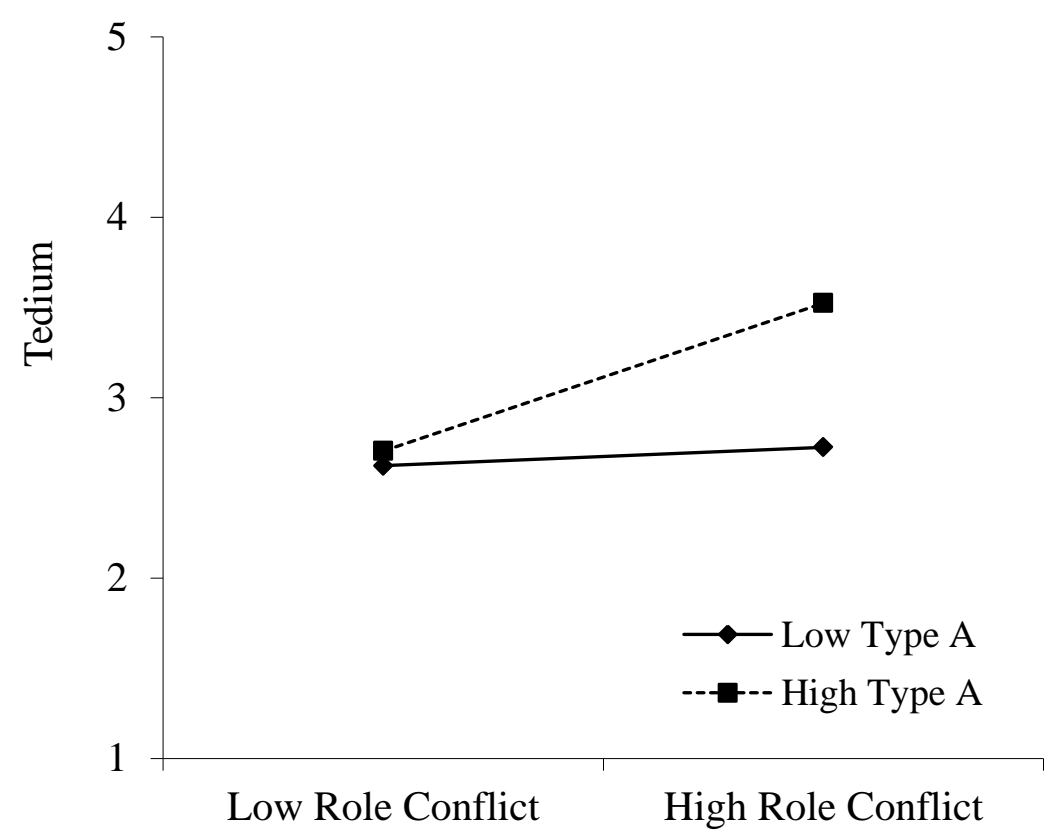

Figure 4. Interaction between TABP and role conflict on tedium.

TABP, role overload, and anxiety. TABP, role overload, and the interaction between TABP and role overload was regressed on anxiety. As stated previously, step one showed that TABP and anxiety are significantly related. For the second step, role overload was entered into the regression analysis and accounted for $22.9 \%$ of the variance in anxiety. The overall relationship between the two independent variables and anxiety was $R^{2}=.23, F(2,133)=19.70$, $p<.001$. Thus, TABP and role overload, as a set, were significantly related to anxiety. The added effect of role overload was $17 \%, \Delta R^{2}=.17, F \Delta(2,133)=29.36, p<.001$. So, adding role overload to TABP accounted for a significant increase in the amount of variance accounted for in anxiety.

For the third step, the interaction between TABP and role overload was entered into the regression analysis and accounted for $25.9 \%$ of variance in anxiety. The overall relationship 
between the two independent variables with the interaction and anxiety was $R^{2}=.26, F(3,132)=$ 15.34, $\mathrm{p}<.001$. Thus, the two independent variables and the interaction between them, as a set, were significantly related to anxiety. The added effect of the interaction was $3 \%, \Delta R^{2}=.03$, $F \Delta(3,132)=5.34, \mathrm{p}<.05$. The interaction between $\mathrm{TABP}$ and role overload accounted for a significant increase in the amount of variance accounted for in anxiety. Figure 5 shows a plot of the slopes, which indicates that as role overload increased, anxiety increased more for Type As than for Type Bs.

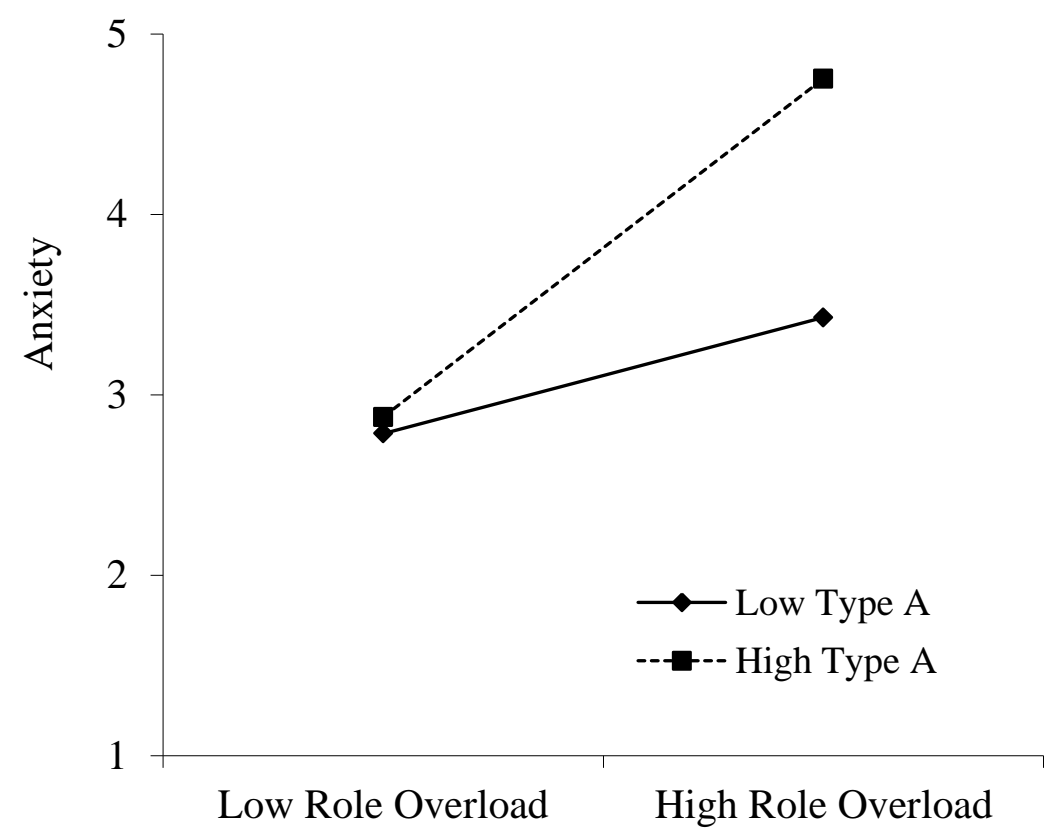

Figure 5. Interaction between TABP and role overload on anxiety.

TABP, role overload, and tedium. TABP, role overload, and the interaction between TABP and role overload was regressed on tedium. As stated previously, step one showed that TABP and tedium are significantly related. For the second step, role overload was entered into the regression analysis and accounted for $18.3 \%$ of the variance in tedium. The overall relationship between the two independent variables and tedium was $R^{2}=.18, F(2,134)=$ 
$15.00, p<.001$. Thus, TABP and role overload, as a set, were significantly related to tedium. The added effect of role overload was $11.6 \%, \Delta R^{2}=.12, F \Delta(2,134)=18.95, p<.001$. So, adding role overload to TABP accounted for a significant increase in the amount of variance accounted for in tedium.

For the third step, the interaction between TABP and role overload was entered into the regression analysis and accounted for $21.2 \%$ of variance in tedium. The overall relationship between the two independent variables with the interaction and tedium was $R^{2}=.21, F(3,133)=$ $11.95, p<.001$. Thus, the two independent variables and the interaction between them, as a set, were significantly related to tedium. The added effect of the interaction was $2.9 \%, \Delta R^{2}=.3$, $F \Delta(3,133)=4.97, p<.05$. The interaction between TABP and role overload accounted for a significant increase in the amount of variance accounted for in tedium. Figure 6 shows a plot of the slopes, which indicates that as role overload increased, tedium increased more strongly for Type As than Type Bs.

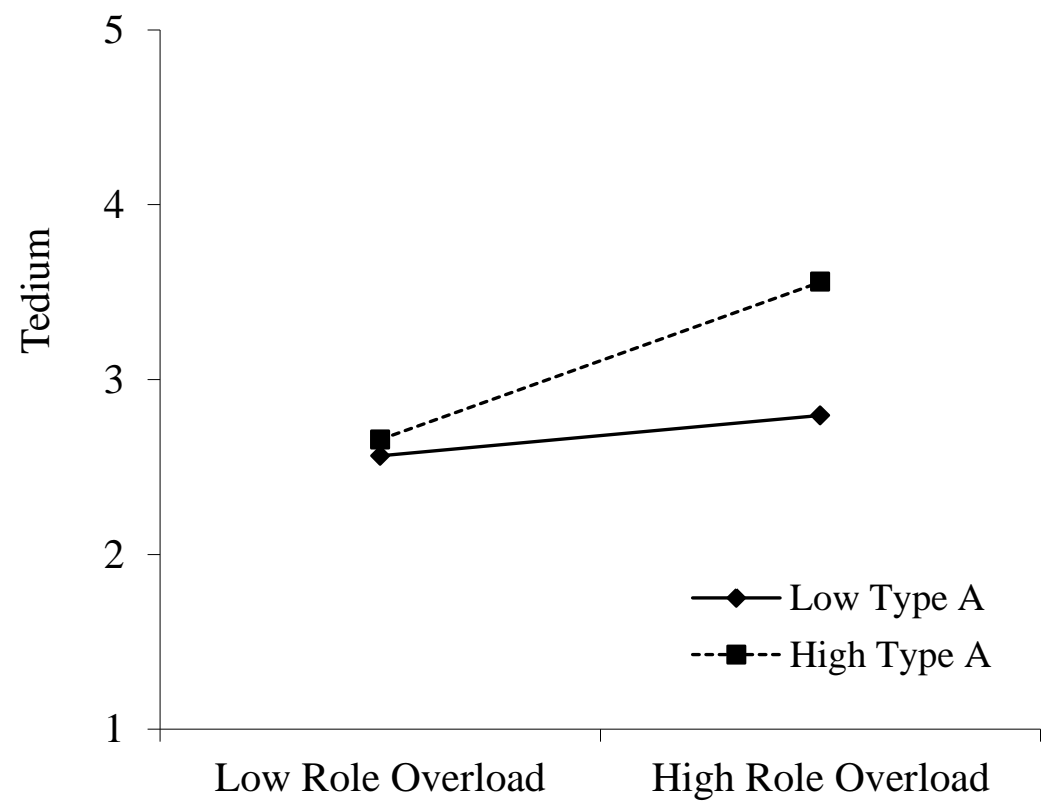

Figure 6. Interaction between TABP and role overload on tedium. 
TABP, role overload, and general well-being. TABP, role overload, and the interaction between TABP and role overload was regressed on general well-being. For the first step, TABP was entered into the regression analysis and it accounted for $1.8 \%$ of the variance in general well-being. The overall relationship between TABP and general well-being was $R^{2}=$ $.02, F(1,134)=2.48, p>.05$. Thus, TABP and general well-being are not significantly related.

For the second step, role overload was entered into the regression analysis and accounted for $7.1 \%$ of the variance in general well-being. The overall relationship between the two independent variables and general well-being was $R^{2}=.07, F(2,133)=5.08, p<.01$. Thus, TABP and role overload, as a set, were significantly related to general well-being. The added effect of role overload was $5.3 \%, \Delta R^{2}=.05, F \Delta(2,133)=7.56, p<.01$. So, adding role overload to TABP accounted for a significant increase in the amount of variance accounted for in general well-being.

For the third step, the interaction between TABP and role overload was entered into the regression analysis and accounted for $9.8 \%$ of variance in general well-being. The overall relationship between the two independent variables with the interaction and general well-being was $R^{2}=.10, F(3,132)=4.77, p<.01$. Thus, the two independent variables and the interaction between them, as a set, were significantly related to general well-being. The added effect of the interaction was $2.7 \%, \Delta R^{2}=.03, F \Delta(3,132)=3.93, p<.05$. The interaction between TABP and role overload accounted for a significant increase in the amount of variance accounted for in general well-being. Figure 7 shows a plot of the slopes, which indicates that as role overload increased, general well-being increased more strongly for Type As than Type Bs. 


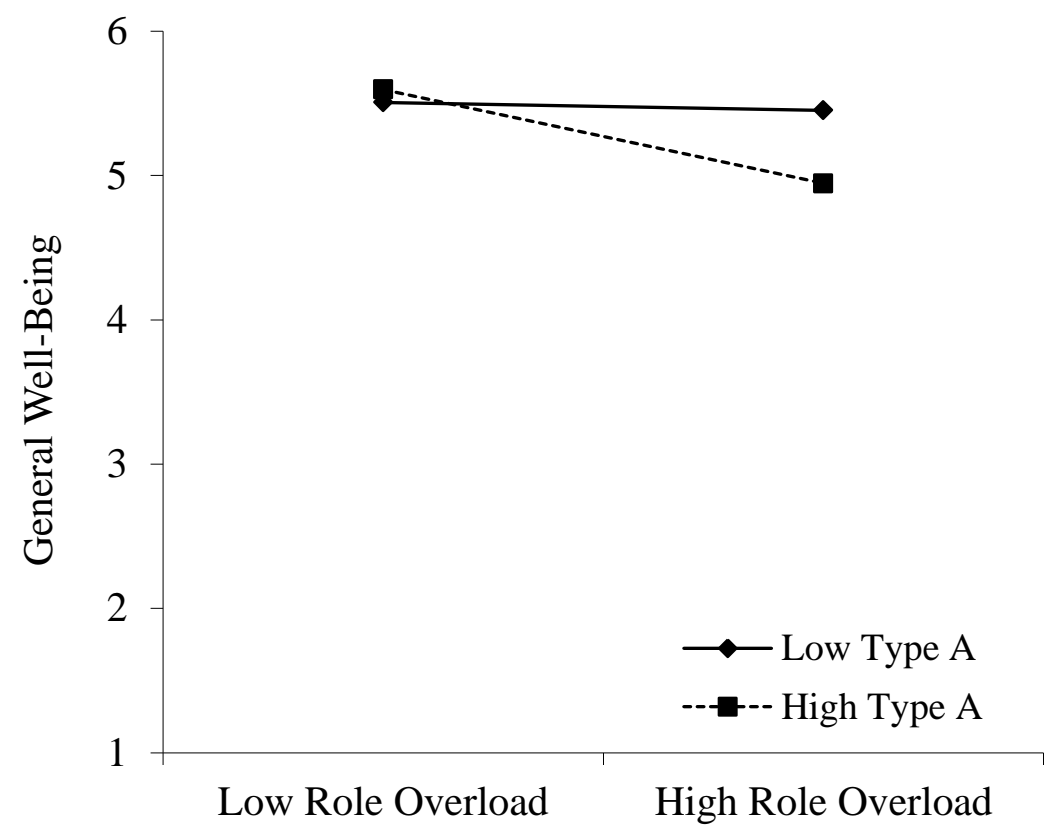

Figure 7. Interaction between TABP and role overload on general well-being.

\section{Post Hoc Analyses}

Though the goal of this study was to assess the effect of TABP on stressors at T1 and strains at T2, prior research by Spector and colleagues (2000) suggests that stressor-strain relationships might be affected by situational factors. In their longitudinal study, the stressorstrain correlations did not change when time administration was controlled. They suggested that interpretations of relationships between job stressors and job strains in cross-sectional surveys are often ambiguous because of possible third variables, such as stable background factors (e.g., personality) and transitory situational factors (e.g., mood). Thus, to determine whether the longitudinal design of this study improved on the detection of the moderating effects of TABP, post hoc analyses were conducted on concurrent stressor-strain relationships (i.e., T1 stressors and $\mathrm{T} 1$ strains). 
The same hierarchical regression analyses were conducted with T1 stressors and T1 strains $(n=137)$. Results of the post hoc analyses indicated that the interaction between TABP and role conflict as well as the interaction between TABP and role overload accounted for significant variance in both anxiety and general well-being. See Table 5 and 6 for full post hoc results. These results suggest an immediate effect of role conflict and role overload on anxiety and general well-being, particularly for Type As.

Post hoc analyses for the T2 stressors and T2 strains were also conducted $(n=217)$. Results of the T2 analyses indicated that the interaction between TABP and role conflict accounted for significant variance in anxiety. See Table 7 and 8 for full post hoc results. This result indicates a concurrent effect of role conflict on anxiety particularly for Type A individuals. Although TABP moderated some of the stressor-strain relationships in both the T1 and T2 survey administration, more of the tested stressor-strain relationships were moderated by TABP over time (i.e., T1 stressors and T2 strains).

\section{Mediated Effects}

Hypothesis 4 stated that role stressors would mediate the relationship between TABP and strain variables. To test Hypothesis 4, both simple and multiple regressions were used. Baron and Kenny (1986) proposed a four-step approach where several regression analyses are conducted to determine whether a mediation effect is present (see Figure 8). Mediation is in effect when: (a) the dependent variable is correlated with the outcome variable (path c); (b) the dependent variable is correlated with the mediator (path a); (c) when the outcome variable is regressed on both the dependent variable and mediator variable, the mediator is correlated with the outcome variable (path b); and (d) the previously significant relationship between the dependent variable and outcome variable is reduced after controlling for the mediator (path c'). 
Table 5

Interaction Between Role Stressors and TABP on Anxiety and General Well-Being - T1 Post Hoc Analysis

\begin{tabular}{lcccccc}
\hline Variable & $\beta$ & $R^{2}$ & $\operatorname{Adj} R^{2}$ & $F$ & $\Delta R^{2}$ & $F \Delta$ \\
\hline Dependent Variable: Anxiety & & & & & & \\
Step 1: TABP & $.20^{*}$ & .04 & .03 & $5.76^{*}$ & .04 & $5.76^{*}$ \\
Step 2: Role Ambiguity & $.33^{* * *}$ & .15 & .14 & $11.72^{* * *}$ & .11 & $16.99^{* * *}$ \\
Role Conflict & $.46^{* * *}$ & .25 & .24 & $22.75^{* * *}$ & .21 & $38.15^{* * *}$ \\
Role Overload & $.52^{* * *}$ & .31 & .30 & $30.23^{* * *}$ & .27 & $52.49^{* * *}$ \\
Step 3: TABP x Role Ambiguity & -.13 & .15 & .13 & $7.78^{* * *}$ & .01 & .06 \\
TABP x Role Conflict & $1.22^{*}$ & .29 & .27 & $17.95^{* * *}$ & .04 & $6.50^{* *}$ \\
TABP x Role Overload & $1.08^{*}$ & .33 & .32 & $22.19^{* * *}$ & .02 & $4.52^{*}$ \\
Dependent Variable: General Well-Being & $-.19^{*}$ & .04 & .03 & $5.20^{*}$ & .04 & $5.20^{*}$ \\
Step 1: TABP & $-.41^{* * *}$ & .20 & .19 & $16.93 * * *$ & .17 & $27.63^{* * *}$ \\
Step 2: Role Ambiguity & $-.33^{* * *}$ & .15 & .13 & $11.56^{* * *}$ & .11 & $17.29^{* * *}$ \\
Role Conflict & $-.35^{* * *}$ & .16 & .15 & $12.50^{* * *}$ & .12 & $19.11^{* * *}$ \\
Role Overload & .29 & .20 & .19 & $11.33^{* * *}$ & .01 & .31 \\
Step 3: TABP x Role Ambiguity & $-1.43^{* *}$ & .19 & .18 & $10.70^{* * *}$ & .05 & $7.82^{* *}$ \\
TABP x Role Conflict & $-1.26^{*}$ & .19 & .17 & $10.28^{* * *}$ & .03 & $5.08^{*}$ \\
TABP x Role Overload & & & & &
\end{tabular}

Note. $* p<.05, * * p<.01, * * * p<.001$. 
Table 6

Interaction Between Role Stressors and TABP on Affective Commitment and Intent to Leave - T1 Post Hoc Analysis

\begin{tabular}{ccccccc}
\hline Variable & $\beta$ & $R^{2}$ & $\operatorname{Adj} R^{2}$ & $F$ & $\Delta R^{2}$ & $F \Delta$ \\
\hline Dependent Variable: Affective Commitment & & & & & \\
Step 1: TABP & -.02 & .01 & -.01 & .08 & .01 & .08 \\
Step 2: Role Ambiguity & $-.27 * *$ & .07 & .06 & $5.28^{* *}$ & .07 & $10.48^{* *}$ \\
Role Conflict & -.16 & .03 & .01 & 1.75 & .03 & 3.43 \\
Role Overload & -.29 & .08 & .07 & $5.91 * *$ & .08 & $11.74 * * *$ \\
Step 3: TABP x Role Ambiguity & .19 & .07 & .05 & $3.53^{*}$ & .01 & .11 \\
TABP x Role Conflict & -.51 & .03 & .01 & 1.45 & .01 & .84 \\
TABP x Role Overload & -.59 & .09 & .07 & $4.27 * *$ & .01 & 1.00 \\
Dependent Variable: Intent to Leave & & & & & & \\
Step 1: TABP & .14 & .02 & .01 & 2.79 & .02 & 2.79 \\
Step 2: Role Ambiguity & $.41^{* * *}$ & .19 & .17 & $15.23^{* * *}$ & .17 & $27.13 * * *$ \\
Role Conflict & $.25 * *$ & .08 & .07 & $5.71^{* *}$ & .06 & $8.86^{* *}$ \\
Role Overload & $.43^{* * *}$ & .20 & .19 & $16.80^{* * *}$ & .18 & $30.20^{* * *}$ \\
Step 3: TABP x Role Ambiguity & -.16 & .19 & .17 & $10.12^{* * *}$ & .01 & .09 \\
TABP x Role Conflict & .53 & .09 & .07 & $4.26^{* *}$ & .01 & .96 \\
TABP x Role Overload & .49 & .21 & .19 & $11.44^{* * *}$ & .01 & .77 \\
\hline
\end{tabular}

Note. $* p<.05, * * p<.01, * * * p<.001$. 
Table 7

Interaction Between Role Stressors and TABP on Anxiety, Tedium, and General Well-Being - T2

Post Hoc Analysis

\begin{tabular}{|c|c|c|c|c|c|c|}
\hline Variable & $\beta$ & $R^{2}$ & $\operatorname{Adj} R^{2}$ & $F$ & $\Delta R^{2}$ & $F \Delta$ \\
\hline \multicolumn{7}{|l|}{ Dependent Variable: Anxiety } \\
\hline Step 1: TABP & $.20 * *$ & .04 & .04 & $8.94 * *$ & .04 & $8.94 * *$ \\
\hline Step 2: Role Ambiguity & $.23 * * *$ & .09 & .09 & $11.10 * * *$ & .05 & $12.77 * * *$ \\
\hline Role Conflict & $.55^{* * *}$ & .33 & .33 & $53.58 * * *$ & .29 & $94.33 * * *$ \\
\hline Role Overload & $.48 * * *$ & .27 & .26 & $39.31 * * *$ & .23 & $66.94 * * *$ \\
\hline Step 3: TABP x Role Ambiguity & .48 & .10 & .09 & $7.75 * * *$ & .01 & 1.32 \\
\hline TABP x Role Conflict & $.66^{*}$ & .35 & .34 & $37.55^{* * *}$ & .01 & $4.00 *$ \\
\hline TABP x Role Overload & .55 & .28 & .27 & $27.14 * * *$ & .01 & 2.32 \\
\hline \multicolumn{7}{|l|}{ Dependent Variable: Tedium } \\
\hline Step 1: TABP & $.18 * *$ & .03 & .03 & $6.98 * *$ & .03 & $6.98 * *$ \\
\hline Step 2: Role Ambiguity & $.33 * * *$ & .14 & .13 & $17.23 * * *$ & .11 & $26.65 * * *$ \\
\hline Role Conflict & $.35 * * *$ & .15 & .14 & $19.07 * * *$ & .12 & $30.22 * * *$ \\
\hline Role Overload & $.42 * * *$ & .21 & .20 & $28.00 * * *$ & .18 & $47.51 * * *$ \\
\hline Step 3: TABP x Role Ambiguity & .21 & .14 & .13 & $11.54 * * *$ & .01 & .28 \\
\hline TABP x Role Conflict & .22 & .15 & .14 & $12.79 * * *$ & .01 & .34 \\
\hline TABP x Role Overload & .20 & .21 & .20 & $18.70 * * *$ & .01 & .29 \\
\hline \multicolumn{7}{|c|}{ Dependent Variable: General Well-Being } \\
\hline Step 1: TABP & -.13 & .02 & .01 & 3.54 & .02 & 3.54 \\
\hline Step 2: Role Ambiguity & $-.47 * * *$ & .24 & .23 & $33.74 * * *$ & .22 & $62.92 * * *$ \\
\hline Role Conflict & $-.33 * * *$ & .12 & .11 & $14.67 * * *$ & .10 & $25.39 * * *$ \\
\hline Role Overload & $-.41 * * *$ & .18 & .17 & $23.73 * * *$ & .17 & $43.23 * * *$ \\
\hline Step 3: TABP x Role Ambiguity & -.12 & .24 & .23 & $22.43 * * *$ & .01 & .10 \\
\hline TABP x Role Conflict & -.66 & .13 & .12 & $10.86^{* * *}$ & .01 & 2.97 \\
\hline TABP x Role Overload & -.48 & .19 & .18 & $16.41 * * *$ & .01 & 1.61 \\
\hline
\end{tabular}

Note. ${ }^{*} p<.05, * * p<.01, * * * p<.001$. 
Table 8

Interaction Between Role Stressors and TABP on Affective Commitment and Intent to Leave - T2

Post Hoc Analysis

\begin{tabular}{lcccccc}
\hline Variable & $\beta$ & $R^{2}$ & $\operatorname{Adj} R^{2}$ & $F$ & $\Delta R^{2}$ & $F \Delta$ \\
\hline Dependent Variable: Affective Commitment & & & & & \\
Step 1: TABP & .06 & .01 & -.01 & .78 & .01 & .78 \\
Step 2: Role Ambiguity & $-.27 * * *$ & .08 & .07 & $9.01 * * *$ & .07 & $17.19^{* * *}$ \\
Step 2: Role Conflict & $-.20^{* *}$ & .04 & .04 & $4.97 * *$ & .04 & $9.12^{* * *}$ \\
Step 2: Role Overload & $-.31^{* * *}$ & .10 & .09 & $11.89 * * *$ & .10 & $22.93^{* * *}$ \\
Step 3: TABP x Role Ambiguity & -.39 & .08 & .07 & $6.30^{* * *}$ & .01 & .88 \\
Step 3: TABP x Role Conflict & .36 & .05 & .04 & $3.58^{*}$ & .01 & .80 \\
Step 3: TABP x Role Overload & -.04 & .10 & .09 & $7.90^{* * *}$ & .01 & .03 \\
Dependent Variable: Intent to Leave & & & & & & \\
Step 1: TABP & .02 & .01 & -.01 & .06 & .01 & .06 \\
Step 2: Role Ambiguity & $.27 * * *$ & .07 & .07 & $8.60^{* * *}$ & .07 & $17.14 * * *$ \\
Step 2: Role Conflict & $.34 * * *$ & .11 & .10 & $13.36 * * *$ & .11 & $26.66 * * *$ \\
Step 2: Role Overload & $.42 * * *$ & .17 & .16 & $22.26^{* * *}$ & .17 & $44.32^{* * *}$ \\
Step 3: TABP x Role Ambiguity & .68 & .09 & .07 & $6.68^{* * *}$ & .01 & 2.69 \\
Step 3: TABP x Role Conflict & .17 & .11 & .10 & $8.94 * * *$ & .01 & .19 \\
Step 3: TABP x Role Overload & .37 & .18 & .16 & $15.09 * * *$ & .01 & .90 \\
\hline
\end{tabular}

Note. ${ }^{*} p<.05, * * p<.01, * * * p<.001$. 


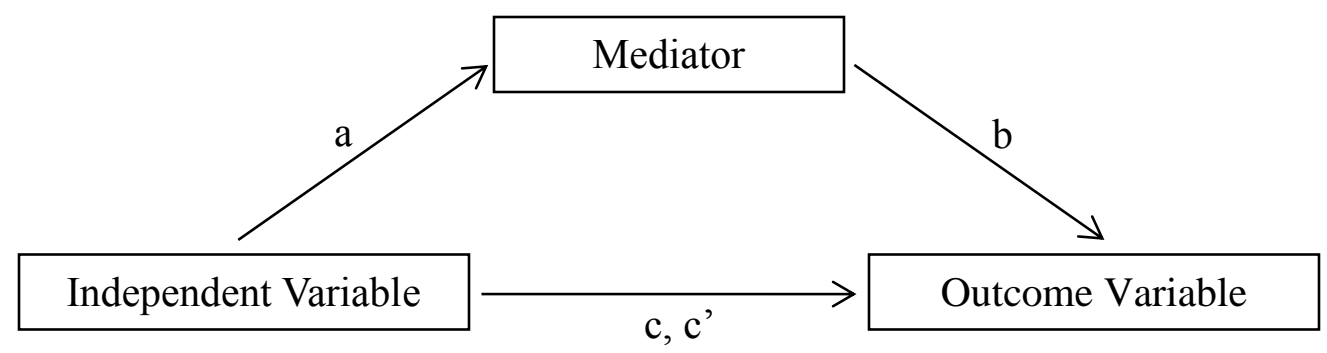

Figure 8. Baron \& Kenny's (1986) mediation model.

Complete mediation occurs when introducing the mediator into the equation reduces the relationship between the dependent and the outcome variables to zero. Partial mediation occurs when the relationship is becomes smaller but not eliminated with the introduction of the mediator. If any of the relationships in steps 1-3 are non-significant, it is concluded that mediation is not present.

Table 9 presents the standardized regression coefficients, their standard errors, and the statistical significance for each of the mediator analyses tested. For Step one of the mediator analysis, fifteen simple regression analyses were conducted where each strain variable (anxiety, affective commitment, intent to leave, general well-being, and tedium) was regressed on each stressor variable (role ambiguity, role overload, and role conflict) to test for path $b$. All role stressor variables were significantly related to all strain variables. For Step two, several regression analyses were run to predict stressors from TABP to test for path a. As seen in Table 9, none of the relationships were significant, indicating that role stressors are not related to TABP. As conditions for mediation were not met in any of the models tested, Hypothesis 4 was not supported. 
Table 9

Tests of stressors as a mediator of the relationships between TABP and Strains

\begin{tabular}{lllll}
\hline Relationships Tested & Path c & Path a & Path b & Path c' \\
\hline TABP $\rightarrow$ Role Ambiguity $\rightarrow$ Anxiety & $.20^{* *}$ & .00 & $.31^{* * *}$ & $.24^{* *}$ \\
TABP $\rightarrow$ Role Ambiguity $\rightarrow$ Tedium & $.18^{* *}$ & .00 & $.26^{* *}$ & $.26^{* *}$ \\
TABP $\rightarrow$ Role Ambiguity $\rightarrow$ General Well-Being & $-.14^{*}$ & .00 & $-.38^{* * *}$ & -.14 \\
$\mathrm{TABP} \rightarrow$ Role Ambiguity $\rightarrow$ Affective Commitment & .07 & .00 & $-.29^{* * *}$ & .07 \\
$\mathrm{TABP} \rightarrow$ Role Ambiguity $\rightarrow$ Intent to Leave & .01 & .00 & $.35^{* * *}$ & .10 \\
$\mathrm{TABP} \rightarrow$ Role Conflict $\rightarrow$ Anxiety & $.20^{* *}$ & .10 & $.39^{* * *}$ & $.20^{* *}$ \\
$\mathrm{TABP} \rightarrow$ Role Conflict $\rightarrow$ Tedium & $.18^{* *}$ & .10 & $.26^{* * *}$ & $.23^{* *}$ \\
$\mathrm{TABP} \rightarrow$ Role Conflict $\rightarrow$ General Well-Being & $-.14^{*}$ & .10 & $-.27^{* * *}$ & -.11 \\
$\mathrm{TABP} \rightarrow$ Role Conflict $\rightarrow$ Affective Commitment & .07 & .10 & $-.18^{*}$ & .09 \\
$\mathrm{TABP} \rightarrow$ Role Conflict $\rightarrow$ Intent to Leave & .01 & .10 & $.22^{* *}$ & .08 \\
$\mathrm{TABP} \rightarrow$ Role Overload $\rightarrow$ Anxiety & $.20^{* *}$ & .05 & $.41^{* * *}$ & $.22^{* *}$ \\
$\mathrm{TABP} \rightarrow$ Role Overload $\rightarrow$ Tedium & $.18^{* *}$ & .05 & $.34^{* * *}$ & $.24 * *$ \\
$\mathrm{TABP} \rightarrow$ Role Overload $\rightarrow$ General Well-Being & $-.14^{*}$ & .05 & $-.23^{* *}$ & -.12 \\
$\mathrm{TABP} \rightarrow$ Role Overload $\rightarrow$ Affective Commitment & .07 & .05 & $-.25^{* *}$ & .08 \\
$\mathrm{TABP} \rightarrow$ Role Overload $\rightarrow$ Intent to Leave & .01 & .05 & $.39^{* * *}$ & .08 \\
\hline N & & & &
\end{tabular}

Notes: $* p<.05, * * p<.01 ; * * * p<.001$ 


\section{Discussion}

This study set out to provide a stronger test of the stressor-strain relationship than has been seen in the typical cross-sectional design dominating much of the stress research. Utilizing a longitudinal design, in which stressors and strains data were collected at two different times, results similar to those of past studies were found (Ackfeldt \& Malhotra, 2013; Glazer \& Beehr, 2005; Glazer \& Kruse, 2008; Örtqvist \& Wincent, 2006). Results indicated that role stressors measured at T1 correlated significantly with strains measured at T2. Each of the three role stressors: role overload, role ambiguity, and role conflict, correlated with the strain variables: anxiety, tedium, turnover intent, affective commitment, and general well-being in the expected direction, providing support for Hypothesis 1. Increases in role stressors lead to increases in anxiety, tedium, and turnover intent, and decreases in affective commitment and general wellbeing. This is in line with much of the stressor-strain research (Ackfeldt \& Malhotra, 2013; Glazer \& Beehr, 2005; Glazer \& Kruse, 2008; Örtqvist \& Wincent, 2006); however, the longitudinal design of this study provides added support for the strength of the relationship.

\section{Implications of the Study}

In addition to examining the direct effects of role stressors on strains, this study also sought to examine the direct effects of TABP on strains. Specifically, it was hypothesized that Type A would positively correlate with anxiety, turnover intention, and tedium, but negatively correlate with affective commitment and general well-being. Hypothesis 2 was partially supported in that Type A positively correlated with anxiety and tedium. These results suggest that in general, Type As tend to experience greater anxiety and tedium than Type Bs.

Jamal and Baba (2003) found similar results. Tedium and anxiety are similar in that they are reactions or feelings of discomfort that are a consequence of stressors. In the case of anxiety, 
the discomfort is due to individual psychological distress or unease (Beehr \& McGrath, 1992) and for tedium, the discomfort may be the experience of emotional, physical, or mental exhaustion (Pines \& Kafry, 1978). A number of studies have linked TABP to burnout, (Alarcon, Eschleman, \& Bowling, 2009; Burke, 1988; Burke \& Greenglass, 1995; Maslach, Schaufeli, \& Leiter, 2001; Nagy, 1985; Nowack, 1987), which as mentioned in the literature review contains one dimension of tedium. Maslach and colleagues (2001) suggest that the exhaustion dimension of burnout is linked to the Type A characteristics of competition, time pressured lifestyle, hostility, and excessive need for control. Additionally, Alarcon and colleagues (2009) suggest that Type A behavior is related to burnout because Types A individuals tend to perceive their work environment negatively, independent of the nature on one's job; and due to their tendency to become easily angry, they tend to perceive even minor or even accidental slights as major injustices.

Lee and Cameron (1986) also found a relationship between anxiety and TABP. They studied the prevalence of Type A personality in patients with anxiety disorder and found that 92\% of the male patients were Type As (this result was not replicated with female anxiety patients). It might be that the characteristic of Type As to work at higher speeds and to experience greater time pressure, taken together with the autonomic arousal potentially activated by the TABP behavior pattern, are subjectively similar to feelings of anxiety (Byrne, 1996).

Results of the post hoc analyses showed that TABP moderated more stressor-strain relationships over time (i.e., $\mathrm{T} 1$ stressors and $\mathrm{T} 2$ strains) than in $\mathrm{T} 1$ or $\mathrm{T} 2$ stressor-strain relationships. Post hoc analyses of T1 stressors to T1 strains showed that TABP moderated the relationships between role conflict and role overload and both anxiety and general well-being. The analysis of T1 stressors on $\mathrm{T} 2$ strains per the original hypothesis revealed an additional 
significant relationship where TABP moderated the relationship between role conflict and role overload with tedium. This could potentially be because Type As tend to ignore, suppress, or deny physical or psychological symptoms while working under pressure, and report symptoms only when the work is finished (Chesney \& Rosenman, 1980). In other words, it is possible that for Type As, the strains reported in $\mathrm{T} 2$ were more a result of $\mathrm{T} 1$ stressors. This may be apparent in that in the T1 stressors and T2 strains analysis, role overload and role conflict were significantly correlated with tedium, which was not seen in the T1 stressors and T1 strains nor the T2 stressors and T2 strains analyses. Pines, Aronson, and Kafry (1981) suggest that tedium can be the result of prolonged chronic pressures (e.g., mental, physical, or emotional) on an individual, indicating that for Type As T1 role overload and role conflict caused psychological strain that was suppressed and manifested itself in increased tedium in T2.

This study also sought to examine the moderating effect of Type A on the stressor-strain relationships. In particular, it was hypothesized that the relationship between role stressors and strains would be higher in Type As than Type Bs. Hierarchical regression analyses yielded significant results for the moderating effect of Type A on the relationships between role conflict and anxiety and tedium, as well as the relationships between role overload and anxiety, tedium, and general well-being. Specifically, these relationships appear stronger for Type As. Looking at the trend of the analyses, the results show that Type As are likely to experience more noxious psychological responses when presented with stressors, but they are not more prone to role stressors than Type Bs.

The results of this study are in line with past research. Spector and colleagues (2000) found that workload stressors related to measures of emotion, including anxiety and frustration, but not with job satisfaction. They stipulate that heavy workloads might result in emotional 
reactions that do not translate into poor job attitudes. Type As tend to feel greater time pressure because they underestimate the amount of time required to do a task (Chesney \& Rosenman, 1980). This could be particularly challenging for Type As when role overload is high if they do not estimate and plan their time accordingly. In addition, Type As tend to ignore, suppress, or deny, physical and psychological symptoms while working under pressure (Chesney \& Rosenman,1980). Thus, when workload is high and Type As are under pressure, they may work through their discomfort, adding to mounting feelings of anxiety or tedium.

The results of this study show that Type A nurses seems to respond more negatively (i.e., increased strains) in response to role conflict and role overload. One reason why Type A nurses may experience greater anxiety and tedium and anxiety is the juxtaposition between their need for control and the nature of the role they play within the hospital's organization. Nurses work under the operational control of physicians and despite having limited decision-making discretion, they generally possess high levels of responsibility (Vredenburgh \& Trinkaus, 1983). However, Type As need to be in control of their immediate environment to such an extent that lack of it may elicit hostile or competitive responses (Newton \& Keenan, 1990). Chesney et al. (1981) found that the work environment that encourages Type As to make their own decisions, take initiative, and carry more responsibility are associated with positive physiological outcomes. Thus, the role of a nurse in itself may be more strain inducing for Type A individuals.

Baron and Kenny (1986) describe a moderator as a variable that affects the direction and/or strength of the relationship between an independent and a dependent variable whereas a mediator accounts for (i.e., explains) the relationship between the independent and dependent variables. TABP acts as a moderator of the stressor-strain relationship in that it affects the strength of the relationship between stressors and strains. No support was found for the role of 
stressors as a mediator of the relationship between TABP and strains. Role stressors (i.e., role conflict, role overload, and role ambiguity) do not explain how TABP relates to strains (i.e., anxiety, tedium, general well-being, affective commitment, and intent to leave). That is, Type As do not experience more strains because they experience more or perceive greater stressors. Full mediation was not expected, but even partial mediation was not found as TABP did not relate to any of the role stressors (the mediators). Each role stressor independently related with each strain-related variable and TABP related with anxiety, general well-being, and tedium. These results indicate that Type As probably do not inherently experience more role stressors than Type Bs; however, in situations of high role conflict and role overload, Type As may react more strongly to the stressors and thus experience or perceive greater amounts of strains (anxiety, tedium, and general well-being in particular) than Type Bs.

\section{Study Strengths and Limitations}

Based on the literature, researchers have theorized that individual differences have an additive effect on the relationship between role stressors and experienced strains. The strength of this study is that it utilizes a holistic framework for examining a third variable (i.e., TABP) in the context of traditional stressor-strain relationship. Three models, as laid out by Kivimaki, Kalimo, and Julkenen (1996), were tested (i.e., the direct effects model, moderated effects model, and mediated effects model) as opposed to validating just one. Support was found for the direct effects and moderated effects models.

Another strength of this study is the longitudinal design. The added support for the moderating effects of TABP from the $\mathrm{T} 1$ to $\mathrm{T} 2$ analysis shows that the inclusion of a longitudinal design might have helped to illumine more of the nature of the relationships than could have been garnered from the standard cross-sectional design. Specifically, in the T1 stressors and T2 
strains analysis, the relationship between role conflict and role overload to tedium was found, which would not have been found if $\mathrm{T} 1$ and $\mathrm{T} 2$ results were studied in isolation.

One of the limitations of this study is the relatively small sample size $(n=137)$. The researchers distributed 1,738 surveys for the study and the response rates for T1 and T2 was $17.43 \%$ and $12.95 \%$, respectively. As this paper called for matched T1 and T2 survey results, only 137 responses were usable - a rate of $7.88 \%$. This small sample size may have contributed to the lack of significant results for hypotheses 3 and 4. This is especially evident for Hypothesis 3 where results were approaching significance. If this study were to be replicated, more effort should be made to encourage participants to complete both surveys.

Relatedly, another potential limitation of the study was the length of the survey and collection method. The survey administered contained several measures not relevant to this particular study. The survey package was eleven pages in total, which may have contributed to the low response rate as participants may have found the survey too time-consuming to complete, despite two free (local) musical theater tickets appended to each survey. In addition, once participants completed their surveys, the collection method may not have been convenient to encourage return of surveys. In one hospital, a collection box was placed in the Chief Nurses' office. As there was only one place to return surveys for a large and dispersed nurse population, some nurses may have found it inconvenient to return or simply forgot to return surveys to the office. In the second hospital, collection envelopes were left at various nursing stations around the hospital. Again, participants may have found it inconvenient or potentially unsecure to locate and drop off completed surveys. In addition, these collection envelopes may have been difficult to find. For future studies, a survey method where nurses are quickly and easily able to complete and return surveys would help to increase response rate. 
Another limitation in this study is the sample of respondents. In certain respects, the sample is somewhat homogenous. About $94 \%$ of the respondents are female, $64 \%$ are married, and $58 \%$ are White. In addition the average age is 50.31 years with a standard deviation of 10.13 years, indicating that the majority of participants are older than 40 years of age. Finally, the majority of the sample is considered high in TABP. TABP was measured on an 11-point scale and the average score was $6.97(\mathrm{SD}=1.35)$. The midpoint of the scale is 5.5 ; and the sample contains about $75 \%$ of participants scoring 6 or higher on TABP. Although according to the Health Resources and Services Administration (2010), this mirrors the nursing population in the USA in terms of sex (i.e., roughly $90 \%$ female RNs), it is not representative of the overall nursing population in the healthcare industry (e.g., average age is $43.6,75 \%$ are White). As such, generalizations made from this study must consider the demographic situation. For future studies, an attempt should be made to obtain data from a more representative sample.

Specifically, U.S. nursing demographic data should be obtained before the survey administration to understand the demographics distributions. As the survey administration is being conducted, surveys should be entered as they are collected and demographics monitored. If the sample is skewed toward one demographic (e.g., females), efforts should be made to encourage participation from the missing demographic sample (e.g., males).

\section{Future Directions for Research}

This study found support for the moderating effect of TABP on the stressor-strain relationship; however, the strains were related to the individual and not the organization. Moderation was not found for affective commitment and intent to leave. In Beehr's and Newman's (1978) model, the significant results were related to the human consequences (i.e., anxiety, tedium, and general well-being) and not to the organizational consequences (i.e., 
affective commitment and turnover intention). Future research should focus on whether TABP moderates the relationship between stressors and organizational consequences. Are there any negative impacts to the organization (e.g., greater turnover or poorer job performance) as a result of having a Type A behavior pattern when experiencing role stressors?

\section{Conclusion}

Nursing is inherently stressful, especially in the area of role conflict and role overload, and nurses tend to be more Type A in their behavior patterns. This study found that Type As experience greater anxiety, intention to leave their organization, and burnout, but less affective commitment and general well-being, regardless of level of stressors. In addition, it was found that Type A nurses experience greater anxiety, tedium, and lower general well-being in response to high role conflict and role overload than Type B nurses. Given these results of the study, we see that not only do Type A nurses experience greater strains in general, in situations where role conflict and role overload are high, the manifestation of strains is even greater. Role conflict and role overload need to be monitored and reduced for nursing staff as it generally leads to poorer outcomes for the majority of the nursing population, as they tend to be Type As. Resources need to be put into place to prevent role stressors in the first place; however, if reducing stressors is not possible, then Type A nurses must be given resources for managing their psychological strain to ensure that it is not prolonged, leading to greater strains down the line. 


\section{References}

Ackfeldt, A., \& Malhotra, N. (2013). Revisiting the role of stress-commitment relationship. European Journal of Marketing, 47, 353-374.

Ajzen, I., \& Fishbein, M. (1977). Attitude-behavior relations: A theoretical analysis and review of empirical research. Psychological Bulletin, 84(5), 888-918.

Alarcon, G., Eschleman, K. J., \& Bowling, N. A. (2009). Relationships between personality variables and burnout: A meta-analysis. Work \& Stress, 23(3), 244-263.

Allen, N. J., \& Meyer, J. P. (1990). The measurement and antecedents of affective, continuance and normative commitment to the organization. Journal of Occupational Psychology, $63,1-18$.

American Psychological Association, Stress in America. (2012). Impact of stress. Retrieved from http://www.apa.org/news/press/releases/stress/2012/impact-report.pdf

American Psychological Association, Stress in America. (2009). Stress in America 2009. Retrieved from https://www.apa.org/news/press/releases/stress/2009/stress-execsummary.pdf

Anton, C. (2009). The impact of role stress on workers' behaviour through job satisfaction and organizational commitment. International Journal of Psychology, 44(3), 187-194.

Azagba, S., \& Sharaf, M. (2011). Psychological working conditions and the utilization of health care services. BMC Public Health, 11, 642-649.

Baron, R. M., \& Kenny, D. A. (1986). The moderator-mediator variable distinction in social psychological research: Conceptual, strategic, and statistical considerations. Journal of Personality and Social Psychology, 51(6), 1173-1182.

Beehr, T. A. (1995). Role ambiguity and role conflict in the workplace. In Psychological stress in the workplace (pp. 55-82). New York, NY: Routledge.

Beehr, T. A., \& Glazer, S. (2005). Organizational role stress. In J. Barling, E. K. Kelloway, \& M. R. Frone (Eds.), Handbook of work stress (pp. 7-33). Thousand Oaks, CA: Sage.

Beehr, T. A., \& McGrath, J. E. (1992). Social support, occupational stress and anxiety. Anxiety, Stress, and Coping, 5, 7-19.

Beehr, T. A., \& Newman, J. E. (1978). Job stress, employee health, and organizational effectiveness: A facet analysis, model, and literature review. Personnel Psychology, 31, 665-669.

Berry, L. M. (1998). Psychology at work. Boston: McGraw-Hill. 
Bolger, N., \& Zuckerman, A. (1995). A framework for studying personality in the stress process. Journal of Personality and Social Psychology, 69(5), 890-902.

Bortner, R. W. (1969). A short rating scale as a potential measure of pattern a behavior. Journal of Chronic Diseases, 22, 87-91.

Bowen, H., \& Wiersema, M. (1999). Matching method to paradigm in strategy research: Limitations of cross-sectional analysis and some methodological alternatives. Strategic Management Journal, 20, 625-636.

Burke, R. J. (1988). Type a behavior, occupational and life demands, satisfaction, and wellbeing. Psychological Reports, 63, 451-458.

Burke, R. J., \& Greenglass, E. R. (1995). Job stressors, type a behavior, coping responses, and psychological burnout among teachers. International Journal of Stress Management, 2, 45-57.

Byrne, D. G. (1996). Type a behavior, anxiety and neuroticism: Reconceptualizing the pathophysiological paths and boundaries of coronary-prone behavior. Stress Medicine, $12,227-238$.

Cammann, C., Fichman, M., Jenkins, D., \& Klesh, J. (1979). The Michigan organizational assessment questionnaire. Unpublished manuscript, University of Michigan, Ann Arbor.

Caplan, R. D., \& Jones, K. W. (1975). Effects of workload, role ambiguity, and type a personality on anxiety depression, and heart rate. Journal of Applied Psychology, 60(6), 713-719.

Chan, Z. C. Y, Tam, W. S., Lung, M. K. Y., Wong, W. Y., \& Chau, C. W. (2013). A systematic literature review of nurse shortage and the intention to leave. Journal of Nursing Management, 21, 605-613.

Chang, E. M., Hancock, K. M., Johnson, A., Daly, J., \& Jackson, D. (2005). Role stress in nurses: Review of related factors and strategies for moving forward. Nursing and Health Sciences, 7, 57-65.

Chesney, M. A., \& Rosenman, R. H. (1980). Type a behaviour in the work setting. In C. L. Cooper, \& R. Payne (Eds.), Current concerns in occupational stress (pp. 187-212). New York: Wiley.

Chesney, M. A., Sevelius, G., Black, G. W., Ward, M. M., Swan, G. E., \& Rosenman, R. H. (1981). Work environment, type a behavior, and coronary heart disease risk factors. Journal of Occupational Medicine, 23, 551-555.

Dearborn, M. J., \& Hastings, A. E. (1987). Type-a personality as a mediator of stress and strain in employed women. Journal of Human Stress, 13, 53-60. 
Duvall, J. J., \& Andrews, D. R. (2010). Using a structured review of the literature to identify key factors associated with the current nursing shortage. Journal of Professional Nursing, 26(5), 309-317.

Fang, Y. (2001). Turnover propensity and its causes among Singapore nurses: An empirical study. International Journal of Human Resource Management, 12(5), 859-871.

Fang, Y., \& Baba, V. (1993). Stress and turnover intention. International Journal of Comparative Sociology, 34(1-2), 24-38.

Fisher, C. D., \& Gitelson, R. (1983). A meta-analysis of the correlates of role conflict and ambiguity. Journal of Applied Psychology, 68(2), 320-333.

Friedman, M., \& Rosenman, R. H. (1974). Type a behavior and your heart. New York: Alfred A. Knopf.

Ganster, D. C., \& Rosen, C. C. (2013). Work stress and employee health: A multidisciplinary review. Journal of Management, 39(5), 1085-1122.

Gelsema, T. I., van der Doef, M., Maes, S., Janssen, M., Akerboo, S., Verhoeven, C. (2006). A longitudinal study of job stress in the nursing profession: Causes and consequences. Journal of Nursing Management, 14, 289-299.

Gilboa, S., Shirom, A., Fried, Y., \& Cooper, C. (2008). A meta-analysis of work demand stressors and job performance: Examining main and moderating effects. Personnel Psychology, 61, 227-271.

Glazer, S. (2005). Six of one, half a dozen of the other: Problems with working fixed and rotating shifts. International Journal of Stress Management, 12(2), 142-163.

Glazer, S., \& Kruse, B. (2008). The role of organizational commitment in occupational stress models. International Journal of Stress Management. 15(4), 329-344.

Goldberg, D. P. (1972). The detection of psychiatric illness by questionnaire. Oxford: Oxford University Press.

Green, A. E., Albanese, B. J., Shapiro, N. M., \& Aarons, A. A. (2014). The roles of individual and organizational factors in burnout among community-based mental health service providers. American Psychological Association, 11(1), 41-49.

Guppy, A., \& Gutteridge, T. (1991). Job satisfaction and organizational stress in the UK general hospital nursing staff. Work \& Stress, 5(4), 315-323.

Healy, C., \& McKay, M. (1999). Identifying sources of stress and job satisfaction in the nursing environment. Australian Journal of Advanced Nursing, 17(2), 30-35. 
House, R. J., \& Rizzo, J. R. (1972). Role conflict and ambiguity as critical variables in a model of organizational behavior. Organizational Behavior and Human Performance, 7, 467505.

Ivancevich, J. M., \& Matteson, M. T. (1984). A type a-b person-work environment interaction model for examining occupational stress and consequences. Human Relations, 37(7), 491-513.

Jackson, S. E., \& Schuler, R. S. (1985). A meta-analysis and conceptual critique of research on role ambiguity and role conflict in work settings. Organizational Behavior and Human Decision Processes, 36, 16-78.

Jamal, M. (1990). Relationship of job stress and type-a behavior to employees' job satisfaction, organizational commitment, psychosomatic health problems, and turnover motivation. Human Relations, 43(8), 727-738.

Jamal, M. (1999). Job stress, type-a behavior, and well-being: A cross-cultural examination. International Journal of Stress Management, 6(1), 57-67.

Jamal, M., \& Baba, V. V. (1992). Shiftwork and department-type related to job stress, work attitudes and behavioral intentions: A study of nurses. Journal of Organizational Behavior, 13, 449-464.

Jamal, M., \& Baba, V. V. (2003). Type a behavior, components, and outcomes: A study of Canadian employees. International Journal of Stress Management, 10(1), 39-59.

Jex, S. M. (2002). Occupational stress. In Organizational psychology: A scientist-practitioner approach (pp. 179-207). New York, NY: John Wiley \& Sons.

Jex, S. M., \& Beehr, T. A. (1991). Emerging theoretical and methodological issues in the study of work-related stress. In G. R. Ferris \& K. M. Rowland (Eds.), Research in personnel and human resources management (Vol. 9, pp. 311-365). Greenwich, CT: JAI.

Jex, S. M., \& Elacqua, T. C. (1999). Self-esteem as a moderator: A comparison of global and organization-based measures. Journal of Occupational and Organizational Psychology, $72,71-81$.

Kahn, R. L. (1980). Conflict, ambiguity, and overload: Three elements in job stress. In D. Katz, R. L. Kahn, \& J. Adams (Eds.) The study of organizations (pp. 418-428). San Francisco, CA: Jossey-Bass.

Keenan, A., \& McBain, G. D. M. (1979). Effects of type a behavior, intolerance of ambiguity, and locus of control on the relationship between role stress and work-related outcomes. Journal of Occupational Psychology, 52, 277-285. 
Kirkcaldy, B. D., \& Martin, T. (2000). Job stress and satisfaction among nurses: Individual differences. Stress Medicine, 16, 77-89.

Kivimaki, M., Kilimo, R., \& Julkunen, J. (1996). Components of type a behavior pattern and occupational stressor-strain relationship: Testing different models in a sample of industrial managers. Behavioral Medicine, 22(2), 67-76.

Lazarus, R. S., \& Folkman, S. (1984). Stress, appraisal, and coping. New York: Springer.

Leatt, P., \& Schneck, R. (1985). Sources and management of organizational stress in nursing sub-units in Canada. Organizational Studies, 6(1), 55-79.

Lee, M. A., \& Cameron, O. G. (1986). Anxiety, type a behavior, and cardiovascular disease. International Journal of Psychiatry in Medicine, 16(2), 123-129.

Maslach, C., \& Jackson, S. E. (1981). The measurement of experienced burnout. Journal of Occupational Behavior, 2, 99-113.

Maslach, C., Schaufeli, W. B., \& Leiter, M. P. (2001). Job burnout. Annual Review of Psychology, 52, 397-422.

Matthews, K. A. (1982). Psychological perspectives on the type a behavior pattern. Psychological Bulletin, 91(2), 293-323.

Meyer, J. P., \& Allen, N. J. (1991). A three-component conceptualization of organizational commitment. Human Resource Management Review, 1, 61-89.

Meyer, J. P., Stanley, D. J., Herscovitch, L., \& Topolnytsky, L. (2002). Affective, continuance, and normative commitment to the organization: A meta-analysis of antecedents, correlates, and consequences. Journal of Vocational Behavior, 61(1), 20-52.

Mowday, R. T., Koberg, C. S., \& McArthur, A. W. (1984). The psychology of the withdrawal process: A cross-validation test of Mobley's intermediate linkages model of turnover in two samples. Academy of Management Journal, 27(1), 79-94.

Muschalla, B., Linden, M., \& Dieter, O. (2010). The relationship between job-anxiety and traitanxiety - A differential diagnostic investigation with the job-anxiety-scale and the stateanxiety-inventory. Journal of Anxiety Disorders, 24, 366-371.

Nagy, S. U. (1985). Burnout: A comparative analysis of personality and environmental variables. Psychological Reports, 57(3), 1319-1326.

National Institute for Occupational Safety and Health, Department of Health and Human Services. (1999). Stress at work. Retrieved from http://www.cdc.gov/niosh/docs/99101/pdfs/99-101.pdf 
National Institute for Occupational Safety and Health, Department of Health and Human Services. (2004). Worker heath chart book. Retrieved from http://www.cdc.gov/niosh/docs/2004-146/pdfs/2004-146.pdf

Newton, T. J., \& Keenan, A. (1990). The moderating effect of the type a behavior pattern and locus of control upon the relationship between change in job demands and change in psychological strain. Human Relations, 43(12), 1229-1255.

Nowack, K. M. (1987). Health habits, type a behavior and job burnout. Work \& Stress, 1(2), 135142.

Örtqvist, D., \& Wincent, J. (2006). Prominent consequences of role stress: A meta-analytic review. International Journal of Stress Management, 13(4), 399-422.

Parker, D. R., \& DeCotiis, T. A. (1983). Organizational determinants of job stress. Organizational Behavior and Human Performance, 32, 160-177.

Parkes, K. R. (1990). Coping, negative affectivity, and the work environment: Additive and interactive predictors of mental health. Journal of Applied Psychology, 75(4), 399-409.

Payne, R. L., Wall, T. D., Borrill, C., \& Carter, A. (1999). Strain as a moderator of the relationship between work characteristics and work attitudes. Journal of Occupational Health Psychology, 1, 3-14.

Pines, A. M., \& Aronson, E. (1988). Career burnout: Causes and cures. New York: Free Press.

Pines, A. M., Aronson, E., \& Kafry, D. (1981). Burnout: From tedium to personal growth. New York: Free Press.

Pines, A., \& Kafry, D. (1978). Occupational tedium in the social services. Social Work, 23(6), 499-507.

Podsakoff, N. P., LePine, J. A, \& LePine, M. A. (2007). Differential challenge stressor-hindrance stressor relationships with job attitudes, turnover intentions, turnover, and withdrawal behavior: A meta-analysis. Journal of Applied Psychology, 92(2), 438-454.

Rosch, P. J. (2001). The quandary of job stress compensation. Health \& Stress, 3, 1-4.

Spector, P. E., Chen, P. Y., \& O’Connell, B. J. (2000). A longitudinal study of relations between job stressors and job strains while controlling for prior negative affectivity and strains. Journal of Applied Psychology, 85(2), 211-218.

Stout, J. K., \& Posner, J. L. (1984). Stress, role ambiguity, and role conflict, Psychological Reports, 55, 747-753. 
Taylor, J. A. (1951). The relationship of anxiety to the conditioned eyelid response. Journal of Experimental Psychology, 41(2), 81-92.

Totterdell, P., Wood, S., \& Wall, T. (2006). An intra-individual test of the demands-control model: A weekly diary study of psychological strain in portfolio workers. Journal of Occupational and Organizational Psychology, 79, 63-84.

U.S. Department of Health and Human Services, Health Resources and Services Administration. (2010). The registered nurse population. Retrieved from http://bhpr.hrsa.gov/healthworkforce/rnsurveys/rnsurveyfinal.pdf

Van den Berg, P. T., \& Schalk, R. (1997). Type a behavior, well-being, work overload, and rolerelated stress in information work. Journal of Social Behavior and Personality, 12(1), 175-187.

Vandenberghe, C., Panaccio, A., Bentein, K., Mignonac, K., \& Roussel, P. (2011). Assessing longitudinal change of and dynamic relationships among role stressors, job attitudes, turnover intention, and well-being in neophyte newcomers. Journal of Organizational Behavior, 32, 652-671.

Vredenburgh, D. J., \& Trinkaus, R. J. (1983). An analysis of role stress among hospital nurses. Journal of Vocational Behavior, 23, 82-95.

World Health Organization, Health Professions Networks Nursing \& Midwifery Human Resources for Health Reference. (2011). A global survey monitoring progress in nursing and midwifery. Retrieved from http://whqlibdoc.who.int/hq/2010/WHO_HRH_HPN_10.4_eng.pdf

Wu, S., Zhu, W., Wang, Z., Wang, M., \& Lan, Y. (2006). Relationship between burnout and occupational stress among nurses in China. Journal of Advanced Nursing, 59(3), 233239. 


\section{Appendix A}

\section{Survey Items}

A self-report paper-pencil survey was administered. Responses to questions pertaining to the stressor and strain variables were rated on a Likert-type scale ranging from 1 to 7 , where 1 is strongly disagree, 2 is disagree, 3 is somewhat disagree, 4 is neither agree not disagree, 5 is somewhat agree, 6 is agree, and 7 is strongly agree.

\section{Role Stressors}

\section{Role Ambiguity}

1. I have clear, planned goals and objectives for my job.

2. I know exactly what is expected of me.

3. Explanation is clear of what has to be done.

\section{Role Conflict}

1. I work with two or more groups who operate quite differently.

2. I receive incompatible requests from two or more people.

3. I do things that are apt to be accepted by one person and not accepted by another.

\section{Role Overload}

1. I receive an assignment without the manpower to complete it.

2. It seems like I have too much work for one person to do.

3. On my present job, the amount of work seems to interfere with how well I can do the job.

4. I often notice a marked increase in my work load.

\section{Strains}

Anxiety

1. Sometimes when I think about my job I get a tight feeling in my chest. 
2. I have felt fidgety or nervous as a result of my job.

3. My job gets to me more than it should.

4. There are lots of times when my job drives me right up the wall.

\section{General Well-Being}

1. I have been able to concentrate on what I am doing.

2. I have lost much sleep over worry.

3. I have felt that I am playing a useful part in things.

4. I have felt capable of making decisions about things.

5. I have felt that I can't overcome my difficulties.

6. I have been able to enjoy my normal day-to-day activities.

7. I have been able to face up to my problems.

8. I have been feeling unhappy or depressed.

9. I have been losing confidence in myself.

10. I have been thinking of myself as a worthless person.

11. I have been feeling reasonably happy, all things considered.

\section{Affective Commitment}

1. This organization has a great deal of personal meaning for me.

2. I do not feel a strong sense of belonging to my organization.

3. I do not feel "emotionally attached" to this organization.

\section{Turnover Intention}

4. I will actively look for a new job in the next year.

5. I often think about quitting.

6. I will probably look for a new job in the next year. 


\section{Tedium}

For the tedium scale, participants were asked to answer the question: When you think about your work overall, how often do you feel the following?, using as scale from 1-7, where 1 is never, 2 is once, 3 is rarely, 4 is sometimes, 5 is often, 6 is usually, and 7 is always.

1. Tired

2. Disappointed with people

3. Hopeless

4. Trapped

5. Helpless

6. Depressed

7. Physically weak/Sickly

8. Worthless/Like a failure

9. Difficulties sleeping

10. "I've had it"

\section{Type A Behavior Pattern}

Participants were asked to circle the number that best reflects the way they behave in your everyday life. For example, on question 1, if they are always on time for appointments, they would circle a number between 7 and 11. If they are usually more casual about appointments, they would circle one of the numbers between 1 and 5.

1. Casual about appointments :: Never late

2. Not competitive :: Very competitive

3. Good listener :: Anticipates what others are going to say (nods, interrupts, finishes for them) 
4. Never feels rushed (even under pressure) :: Always rushed

5. Can wait patiently :: Impatient when waiting

6. Casual :: Eager to get things done

7. Take things one at a time :: Tries to do many things at once, thinks what he/she will do next

8. Slow, deliberate talker :: Emphatic in speech (fast and forceful)

9. Cares about satisfying him/herself no matter what others may think :: Wants good job recognized by others

10. Slow doing things :: Fast (eating, etc.)

11. Easy going :: Hard driving (pushing self and others)

12. Expressive :: Hides feelings

13. Many outside interests :: Few interests (out of work/home)

14. Unambitious :: Ambitious 